\title{
A physiologically-based pharmacokinetic model of oseltamivir phosphate and its carboxylate metabolite for rats and humans
}

\author{
Guanghua Gao ${ }^{1,3 *}$, Francis Law ${ }^{2}$, Ricky Ngok Shun Wong ${ }^{3}$, Nai Ki Mak ${ }^{3}$, Mildred Sze \\ Ming Yang ${ }^{3}$ \\ ${ }^{1}$ Center for Drug Evaluation, China Food and Drug Administration, Beijing 100022, China; \\ ${ }^{2}$ Department of Biological Sciences, Simon Fraser University, Burnaby, B.C. Canada V3N 4W8; \\ ${ }^{3}$ Department of Biology, Hong Kong Baptist University, Kowloon, Hong Kong. SAZ. China.
}

*Corresponding Author: E-mail: gaogh@cde.org.cn; Tel.: 010-85243575

Received: October 30, 2018; Revised: January 31, 2019; Published: February 23, 2019

\begin{abstract}
Oseltamivir phosphate (OP, Tamiflu $\left.{ }^{\circledR}\right)$ is a widely used prodrug for the treatment of influenza viral infections. Orally administered $O P$ is rapidly hydrolyzed by the carboxylesterases in animals to oseltamivir carboxylate (OC), a potent influenza virus neuraminidase inhibitor. The goals of this study were to develop and validate a physiologically-based pharmacokinetic (PBPK) model of OP/OC in rats and humans, and to predict the internal tissue doses for $O P$ and $O C$ in humans after receiving $O P$ orally. To this end, a $P B P K$ model of $O P / O C$ was first developed in the rat, which was then scaled up to humans by replacing the physiological and biochemical parameters with human-specific values. The proposed PBPK model consisted of an OP and an OC sub-models each containing nine first-order, flow-limited tissue/organ compartments. $O P$ metabolism to OC was assumed to carry out mainly by hepatic carboxylesterases although extrahepatic metabolism also occurred especially in the plasma. The PBPK model was developed and validated by experimental data from our laboratories and from the literature. The proposed PBPK model accurately predicted the pharmacokinetic behavior of $O P$ and $O C$ in humans and rats after receiving a single or multiple doses of OP orally or an OC dose i.v. The PBPK model was used to predict the internal tissue doses of $O P$ and $O C$ in a hypothetical human after receiving the recommended dose of $75 \mathrm{mg} / \mathrm{kg}$ OP b.i.d. for 6 days. Steady-state OC concentrations in the plasma and major organs such as the lung and the brain were higher than the minimum in vitro IC50 reported for H1N1 influenza virus neuraminidase, confirming OP is an effective, anti-viral agent. OP side-effects in the gastrointestinal tract and brain of humans were explainable by the tissue doses found in these organs. The PBPK model provides a quantitative tool to evaluate the relationship between an externally applied dose of $O P$ and the internal tissue doses in humans. As such the model can be used to adjust the dose regimens for adult patients in disease states e.g., renal failure and liver damage.
\end{abstract}

\section{Keywords}

Oseltamivir; physiologically-based pharmacokinetic modelling; tissue concentration; dose metrics

\section{Introduction}

Oseltamivir phosphate (OP, Tamiflu $\left.{ }^{\circledR}\right)$ is an effective prodrug for the prevention and treatment of influenza viral infection [1]. After oral dosing, OP is rapidly absorbed into the systemic circulation of humans and hydrolyzed by the carboxylesterase enzymes in different tissues and organs to oseltamivir carboxylate (OC), a potent inhibitor of the neuraminidase enzyme [2] (Fig. 1). Because influenza virus needs 
neuraminidase to grow and duplicate, $\mathrm{OC}$ is able to reduce the duration and severity of influenza viral infection in humans [3].

$\mathrm{OP}$ is a drug with a wide margin of safety. However, adverse events such as abdominal pain, diarrhea, nausea, and skin reaction have been reported during early medication periods especially if the oral dose is $>200$ mg OP b.i.d. [3,4]. Thus neurological symptoms such as headache, vertigo, somnolence, insomnia, numbness, hyper-excitation and an increase in suicidal tendency also have been reported in Japanese children and young adolescents [5,6]. The mechanism(s) by which OP causes neuropsychiatric effects remains unclear: Toovey et al. [7] have suggested that since OP and OC are P-glycoprotein substrates [8], little or no $\mathrm{OP} / \mathrm{OC}$ is able to penetrate the blood-brain barrier of humans and cause neuropsychiatric effects [9]. Conversely, OP has been shown to block ganglioside-regulated excitatory opioid receptormediated hyperalgesia and increase opioid analgesia in mice $[10,11]$. Thus, OP or OC may alter the neuronal excitability of the brain by increasing the synchronization of hippocampus network [12]. It is also possible that $\mathrm{OP} / \mathrm{OC}$ change human behaviors if the blood-brain barrier is immature or damaged as in the case of young children.

OP metabolic disposition has been studied in rats [13], ferrets [14] and mice [15]. The oral bioavailability of OP in these animals ranges from 30-73\% [16] but in humans, it may reach $80 \%$. Therapeutic levels of OC have been found in the lungs, trachea, nasal mucosa of ferrets [14], and the middle ear and sinuses of humans [17]. However, little or no information is available on the dose metrics of $O P$ and $O C$ in the internal tissues/organs of humans. Andersen [18] has suggested using the physiologically based pharmacokinetic (PBPK) model to predict the pharmacokinetics and tissue doses of environmental chemicals in humans. Moreover, by determining the relationship between the internal tissue dose (instead of the external dose) and the pharmacological or toxicological effects of xenobiotics, we can greatly improve the accuracy of the dose-response relationship of prescription drugs and chemicals [19].

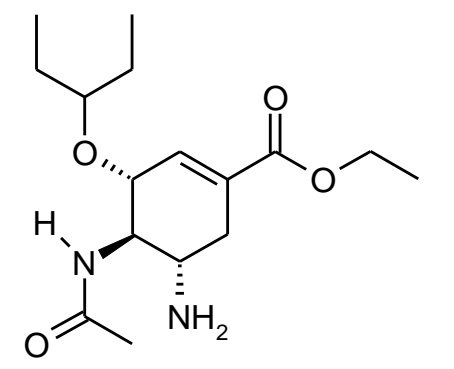

Oseltamivir phosphate (OP)

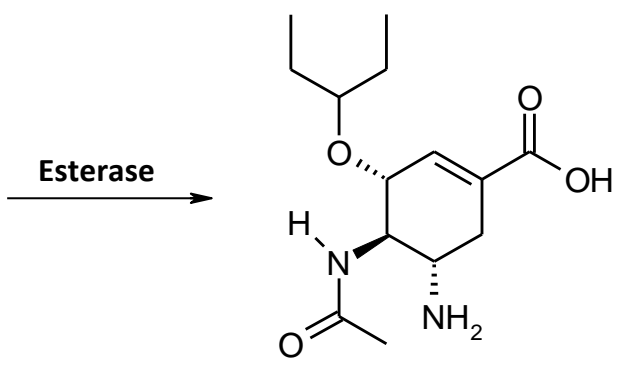

Oseltamivir carboxylate (OC)

Figure 1. Hydrolysis of oseltamivir phosphate to oseltamivir carboxylate

Hitherto, at least two different OP PBPK models have been reported for neonates, infants and adult humans $[20,21]$. None of these models have been used to predict an internal tissue dose of OP/OC in humans. Parrott et al. [20] first develop an OC PBPK model in marmoset monkeys and then extrapolate the model to young children. The PBPK model was developed using a multi-compartment permeability-limited liver. Due to a lack of tissue distribution data in monkeys and humans, the PBPK model needs refinement and improvement.

The aims of this study were to develop and validate a PBPK model for OP/OC in rats, to scale up the rat model to humans, and to predict the internal tissue doses of $O P / O C$ in rats and humans using peak concentration $\left(C_{\max }\right)$ and/or area under the curve $\left(A \cup C_{\text {plasma }}\right)$ of concentration-time curve as the dose 
surrogates. Attempts were made to explain the therapeutic and/or side effects of OP in humans using the model-predicted dose metrics. Since our OP/OC PBPK model is based on the actual anatomy and physiology of rats (or humans) and the physicochemical properties of OP/OC, it should be useful in predicting the internal tissue doses of $\mathrm{OP} / \mathrm{OC}$ across the external doses, administration routes, and animal species [22].

\section{Materials and methods}

\section{Metabolic disposition of $O P$ in the rat}

Chemicals. OP/OC standards were kindly donated by Hoffmann-La Roche Ltd., Switzerland. Chemical purity of both chemicals exceeded $99 \%$. Dichlorvos was purchased from Supelco (Bellfonte, PA, US). Analytical grade diethyl ether and HPLC grade acetonitrile were purchased from Labscan Asia Co. Ltd (Bangkok, Thailand).

Animals. Male Sprague-Dawley rats weighing about $250 \mathrm{~g}$ were purchased from the Chinese University of Hong Kong, Hong Kong. The animals were maintained on a constant light-dark cycle with light from 07:00 to 19:00 $\mathrm{h}$ and darkness from 19:00 to 07:00 $\mathrm{h}$. Tap water and food were provided ad libitum. The rats were used after a 7-day acclimation period. The procedure associated with animal care and experimentation was carried out according to the Hong Kong Council on Animal Care guidelines and with formal approval of the Animal Care Committee of the Hong Kong Baptist University.

Tissue distribution studies. Thirty rats were used in the tissue distribution studies. The rats were assigned randomly into two groups of 15 rats each. After fasting overnight, one group of rats were given a single dose of $10 \mathrm{mg} / \mathrm{kg}$ OP by gavage. The other group of rats received $50 \mathrm{mg} / \mathrm{kg}$ OP. Three rats from each group were selected randomly and euthanized by diethyl ether at the following time points: $0.5,2,3,6$, and $12 \mathrm{~h}$ post-dosing for the $10 \mathrm{mg} / \mathrm{kg}$ dose group; 0.5, 2, 3, 6 and $10 \mathrm{~h}$ post-dosing for the $50 \mathrm{mg} / \mathrm{kg}$ dose group. The abdominal wall was opened and a blood sample was withdrawn by cardiac puncture. The blood samples were centrifuged immediately at $3000 \mathrm{rpm}$ for $10 \mathrm{~min}$ to collect the plasma. The plasma was put in a centrifuge tube containing a mixture of sodium heparin and dichlorvos which was used to inhibit OP hydrolysis in the sample [23]. The liver, spleen, lung, and kidney were also removed from the rats. The tissue samples were rinsed briefly with distilled water, wiped dry with Kimwipes, and stored at $-80{ }^{\circ} \mathrm{C}$ until analysis.

Extraction of $\mathrm{OP}$ and $\mathrm{OC}$ from plasma and tissue samples. One gram of tissue/organ ( $0.5 \mathrm{~g}$ for spleen) was weighed accurately in a test tube. After adding distilled water $(3 \mathrm{ml})$ and dichlorvos $(600 \mu \mathrm{g})$, the tissue/organ was homogenized in a Kinemetica GmbH homogenizer (PCU-2-110, Switzerland) for about 2 min. A $0.2 \mathrm{ml}$ aliquot of the tissue homogenate (or plasma) was added to $0.8 \mathrm{ml}$ of acetonitrile/water (3:1, $\mathrm{v} / \mathrm{v}$ ) in an Eppendorf tube. The content in the Eppendorf tube was mixed by vortex for $1 \mathrm{~min}$ and then centrifuged at $13000 \mathrm{rpm}$ for $10 \mathrm{~min}$. The supernatant was removed and stored at $-80{ }^{\circ} \mathrm{C}$ until analysis.

LC/MS/MS analysis of OP and OC. Frozen tissue extracts were thawed, diluted with the mobile phase, and injected $10.0 \mu \mathrm{l}$ of the final solution into the HPLC. OP/OC in the extracts was quantified using a modified LC/MS/MS procedure reported by Lindegardh et al. [24]. Briefly, OP/OC separation was performed on a $\mathrm{C} 18$ analytical column (ODS-2, 150mm, 5u, Waters Corp. Milford, MA) in a HP 1100 system (Hewlett Packard, Santa Clara, California) preceded by a guard column (2.1 by $5 \mathrm{~mm}$; particle size, $1.7 \mu \mathrm{m}$ ) (Waters Corp. Milford, MA). The column was maintained at $26^{\circ} \mathrm{C}$; it was eluted isocratically at a flow rate of $0.200 \mathrm{ml} / \mathrm{min}$. The HPLC mobile phase consisted of a solution with an equal volume of ammonium 
formate $(8.0 \mathrm{mM})$ and methanol. The solution was adjusted to $\mathrm{pH} 3.50$ with formic acid. The analysis employed an API 3200TM triple quadrupole mass spectrometer (AP Scienx) equipped with a Turbo VTM ion source controlled by the LINAC $^{\circledR}$ collision cell technology for output scanning. The optimal transitions were $313.14 \mathrm{~m} / \mathrm{z}$ to $224.92 \mathrm{~m} / \mathrm{z}$ for OP, $285.2 \mathrm{~m} / \mathrm{z}$ to $197.0 \mathrm{~m} / \mathrm{z}$ for OC. The limits of detection for OP and OC were 20 and $30 \mathrm{pg} / \mathrm{ml}$, respectively. The limits of quantification ranged from 0.4-0.6 ng/ml for plasma and 1.6-2.4 ng/g for tissues. Recoveries were achieved by comparing OP/OC concentration in the extract to the theoretical concentration; they ranged from $96 \%$ to $101 \%$ in the plasma/tissue samples. No obvious matrix effects were detected in the tissues within the OP/OC concentration ranges used in this study.

Blood to plasma ratio. About $2 \mathrm{ml}$ of freshly drawn rat blood was mixed with a solution containing of $100 \mu \mathrm{g} / \mathrm{ml} \mathrm{OP}$ (or OC) standard and $200 \mu \mathrm{g} / \mathrm{ml}$ of dichlorvos. Preliminary studies indicated that equilibrium between the plasma and blood for OP/OC was established within $20 \mathrm{~min}$. After incubating the whole blood at $37^{\circ} \mathrm{C}$ for $30 \mathrm{~min}$, an aliquot was removed and centrifuged at $3000 \mathrm{rpm}$ for $10 \mathrm{~min}$ to obtain the plasma. $\mathrm{OP}$ and $\mathrm{OC}$ concentrations in the plasma were measured by LC/MS/MS as described above. OP and OC concentrations in the blood were assumed to be the theoretical concentrations. Blood/plasma concentration ratio (BLPLR) was calculated by dividing the concentration of OP (or OC) in the whole blood with that in the plasma. The BLPLR of OP and OC was about 1.0 which indicated OP and OC had similar protein binding capacities to blood and plasma.

OP metabolism by rat plasma in vitro. In vitro OP metabolism was studied by incubating different concentrations of OP solution $(0.1-0.5 \mathrm{mg} / \mathrm{ml})$ with $30 \mu \mathrm{l}$ rat plasma and Tris- $\mathrm{HCl}$ buffer $(\mathrm{pH} 7.4)$ in a shaking water bath maintained at $37^{\circ} \mathrm{C}$. The final incubation volume was $200 \mu$ l. Control incubation was carried out in a similar manner but without rat plasma. At $1 \mathrm{~h}$ after incubation, ice-cold acetonitrile ( $400 \mu \mathrm{l})$ was used to terminate the hydrolysis reaction. The mixture was centrifuged at $13200 \mathrm{rpm}$ in a $4{ }^{\circ} \mathrm{C}$ centrifuge (Model 5415R, Eppendorf AG, Barkhausenweg 122339 Hamburg, Germany) for 10 min to separate into layers. The supernatant was transferred to an HPLC vial and analyzed by a Hewlett Packard 1100 HPLC equipped with a UV detector. OP and OC were separated on an HPLC column (ODS-2, $150 \mathrm{~mm}$, $5 \mu \mathrm{m}$ ) using gradient elution. The mobile phase consisted of a solution of $0.4 \%$ phosphoric acid (pH 3.0) and acetonitrile $(80: 20, \mathrm{v} / \mathrm{v})$. Acetonitrile in the mobile phase increased linearly from $20 \%$ to $40 \%$ in $10 \mathrm{~min}$. The flow rate of the mobile phase was $1 \mathrm{ml} / \mathrm{min}$. The detection wavelength was set at $215 \mathrm{~nm}$. OP metabolism rate was expressed as $\mu \mathrm{g} O C$ formed $/ \mathrm{ml}$ plasma/h. The $V_{\max }$ and $K_{\mathrm{m}}$ of OP metabolism were determined using the Lineweaver-Burke plot and were found to be $61.2 \mathrm{mg} / \mathrm{h}$ and $300 \mathrm{mg} / \mathrm{L}$, respectively.

\section{PBPK modeling of OP/OC in rats and humans}

Model structure. Fig. 2 shows a schematic diagram of the OP/OC PBPK model in rats after oral administration. The PBPK model actually consisted of an OP sub-model and an OC sub-model. Each submodel was composed of 9 first-order flow-limited tissue compartments: the lung, kidney, muscle, brain, liver, spleen, gut, blood and rest of body. The brain was lumped with the fat and the lung was lumped with the heart because of possible similar tissue/plasma partition coefficients. The rest of body compartment included all other tissues which had not been identified in the model i.e., the skin, bone, eye, prostate gland, etc. The lung and the brain are modeled as separate compartments because H5N1 influenza virus mainly affected the respiratory tract and the central nervous system of Japanese children after oral administration of OP [5,6]. Absorption of OP was assumed to be a linear, first-order input process. After absorption, OP was hydrolyzed to OC mainly by the carboxylesterases in the plasma and the liver. For the purpose of model development, OP metabolism was assumed to occur only in the liver which linked the OP and OC sub-models together (Fig. 2). Also, one mole of OP was converted by the carboxylesterase 
enzymes to one mole of OC. Both OP and OC were excreted into the urine by the kidney.

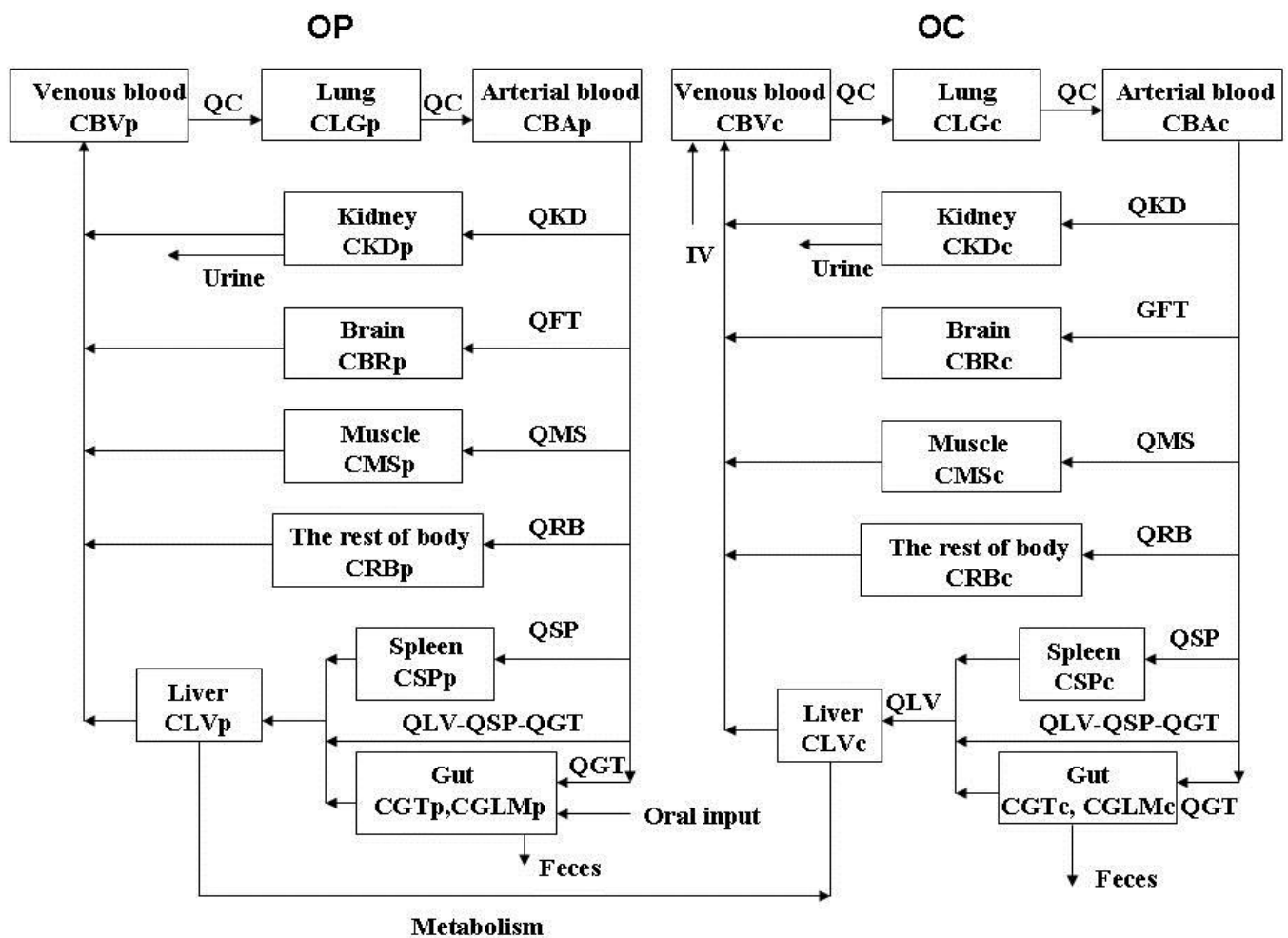

Figure 2. Schematic diagram of the physiologically-based pharmacokinetic model for rats or humans after OP administration. C represents OP or OC concentrations ( $\mathrm{ng} / \mathrm{g}$ or $\mathrm{ng} / \mathrm{ml})$; $\mathrm{Q}$ represents plasma flow rates $(\mathrm{l} / \mathrm{h})$. The subscripts ( $p$ or $c$ ) under specific tissue concentration $C$ in the sub-models refer to OP or OC, respectively

Physiological parameters. The physiological parameters of the rat PBPK model were parameterized $a$ priori (Table 1) as follows: tissue volume and blood flow were taken from Luttringer et al. [25] and from Davies and Morris [26]; these parameter values were expressed as the percentage of total body volume or cardiac output (CO). Total blood volume was divided into a two-thirds venous pool and one-third arterial pool. Gut content volumes was assumed to be $0.014 \mathrm{~L}$ for a $0.25 \mathrm{~kg}$ rat [27].

Pharmacokinetic parameters. Absorption rate constant $\left(k_{\mathrm{a}}\right)$ of OP was determined to be $0.76 \mathrm{~h}^{-1}$ which was obtained by fitting the $O C$ concentration-time curve in plasma following oral administration of $10 \mathrm{mg} / \mathrm{kg}$ of OP to a classical, one-compartment pharmacokinetic model. Considering the uncertainty of the absorption related parameters, $F$ and $K_{\mathrm{a}}$ were allowed to be optimized to a reasonable extent during the modelling process based on the individual experimental datasets (Table 2). The oral bioavailability of OP was reported to be 0.35 calculated by $A \cup C_{\text {p.o. }}(\mathrm{OP}) / A \cup C_{i . .}(\mathrm{OC})$ ratio, it should be noticed that in the PBPK model $F$ represents the oral bioavailability factor which was derived from the integrative modeling process of the PBPK model for all organs [28] and might be different from the experimental absolute bioavailability $\left(A \cup C_{\text {p.o. }} / A \cup C_{\text {i.v. }}\right.$ ). The clearance $(C L C)$ of $O C$ from rats was reported to be $0.38 \mathrm{~L} / \mathrm{h}$ after injecting a single dose of $10 \mathrm{mg} / \mathrm{kg}$ intravenously $[15,16]$. In vitro $K_{\mathrm{m}}(300 \mathrm{mg} / \mathrm{L})$ and $V_{\max }(61.2 \mathrm{mg} / \mathrm{h})$ values were obtained by incubating OP with rat plasma. Fecal excretion rate constant $\left(k_{\mathrm{f}}\right)$ was assumed to be $1 /$ transit time of the small intestine; the transit time of the small intestine was taken from Davies and Morris [26]. 
Table 1. Physiological parameters of the OP/OC PBPK model in rats and humans ${ }^{*}$

\begin{tabular}{|c|c|c|c|c|c|c|}
\hline \multirow{2}{*}{$\begin{array}{c}\text { Parameter } \\
\text { Tissue } \\
\end{array}$} & \multicolumn{2}{|c|}{$\begin{array}{c}\text { Organ weight (\% of body } \\
\text { weight) }\end{array}$} & \multicolumn{2}{|c|}{$\begin{array}{l}\text { Regional blood flow (\% of } \\
\text { cardiac output) }\end{array}$} & \multicolumn{2}{|c|}{ Partition coefficients } \\
\hline & Rat & Human & Rat & Human & OP & OC \\
\hline Adipose & 7.6 & 12 & 7 & 5 & & \\
\hline Brain & 0.57 & 0.2 & 2 & 12 & & \\
\hline Lumped brain & 8.13 & 12.2 & 9 & 17 & 0.5 & 0.25 \\
\hline Heart & 0.33 & 0.47 & & & & \\
\hline Lung & 0.5 & 0.76 & & & & \\
\hline Lumped lung & 0.83 & 1.23 & & & 2.5 & 0.5 \\
\hline Kidney & 0.73 & 0.44 & 14.1 & 19 & 5 & 8 \\
\hline Liver & 3.66 & 2.57 & 32.6 & 25 & 3 & 5 \\
\hline Gl tract & 2.7 & 1.7 & 13.1 & 17 & 10 & 1 \\
\hline Muscle & 40.4 & 40 & 27.8 & 17 & 1.4 & 0.5 \\
\hline Spleen & 0.2 & 0.26 & 2 & 2 & 1.5 & 0.5 \\
\hline The rest of body ${ }^{* *}$ & 43.4 & 41.6 & 16.5 & 22 & 3 & 1 \\
\hline Total & 100 & 100 & 100 & 100 & & \\
\hline
\end{tabular}

"Mean data on tissue blood flow rate and volume were adapted from Luttringer et al. [25]. Organ weight was based on the mean BW of a $0.26 \mathrm{~kg}$ rat and a $70 \mathrm{~kg}$ human; Cardiac output for a $0.25 \mathrm{~kg}$ rat is $4.99 \mathrm{~L} / \mathrm{h}$; it is calculated from the equation, $14.1 * \mathrm{BW}^{0.75}(\mathrm{~L} / \mathrm{h})$. Cardiac output for a $70 \mathrm{~kg}$ human is $390 \mathrm{~L} / \mathrm{h}$; it is calculated from the equation, $16.1 * \mathrm{BW}^{0.75}(\mathrm{~L} / \mathrm{h})$.

** The brain was lumped into the adipose tissues to form the "brain compartment"; the lung was lumped into the heart to form the "lung compartment"; the remaining organs/tissues including the bone, skin, eye, etc., were grouped together to form "the rest of body".

Table 2. Pharmacokinetic parameters for the OP PBPK model of rats and humans

\begin{tabular}{|c|c|c|c|c|}
\hline \multicolumn{5}{|c|}{ Chemical specific parameters } \\
\hline Molecular weight & \multirow{2}{*}{\multicolumn{3}{|c|}{$\begin{array}{l}\text { oseltamivir phosphate salt (OP):410.4 } \\
\text { oseltamivir carboxylate (OC): } 284.35 \\
\text { OP: } 53.7 \% \text { (rat); } 57 \text { (human); } \\
\text { OC: no data (rat); } 97 \% \text { (human) }\end{array}$}} & \multirow{2}{*}{$\begin{array}{l}\text { Used in model } \\
\text { Not used in model, for } \\
\text { reference }\end{array}$} \\
\hline $\begin{array}{l}\text { Unbound fraction in } \\
\text { plasma }\end{array}$ & & & & \\
\hline \multicolumn{5}{|c|}{ PK parameters } \\
\hline & \multicolumn{2}{|c|}{ Rat } & \multicolumn{2}{|c|}{ Human } \\
\hline Parameter & Experimental & Optimized & Experimental & Optimized \\
\hline$F$ & 0.35 & $0.8-0.86$ & 0.75 & 0.75 \\
\hline$T_{\text {lag }}(\mathrm{h})$ & NA & $0.32-0.44$ & NA & 0.44 \\
\hline Ka $(1 / \mathrm{h})$ & 0.76 & $12-15$ & NA & $\begin{array}{c}0.35 \\
(0.14-0.28)^{* * *}\end{array}$ \\
\hline $\mathrm{BLPLR}_{\mathrm{p}}$ & 1 & 1 & NA & 1 \\
\hline $\mathrm{BLPLR}_{\mathrm{c}}$ & 1 & $1(0.7) * *$ & NA & $1(0.6)^{* *}$ \\
\hline $\mathrm{CL}_{\mathrm{c}}(\mathrm{L} / \mathrm{h})$ & 0.38 & $0.38(0.5) * *$ & 18 & $18(30)^{* *}$ \\
\hline $\mathrm{CL}_{p}(\mathrm{~L} / \mathrm{h})$ & NA & 0.4 & 20 & 100 \\
\hline$K_{\mathrm{m}}(\mathrm{mg} / \mathrm{L})$ & 300 & 300 & $76.0 * * * *$ & $76.0 * * * *$ \\
\hline$V_{\max }(\mathrm{mg} / \mathrm{h})^{*}$ & 61.2 & 61.2 & $2.6 \times 10^{5} * * * *$ & $2.6 \times 10^{5} * * * *$ \\
\hline
\end{tabular}

${ }^{*} V_{\max }$ was based on a $0.25 \mathrm{~kg}$ rat and a $70 \mathrm{~kg}$ human

**Bracketed parameter values were used for the i.v. route of administration

***Bracketed parameter values were used for multiple oral administration; they were obtained by optimizing the plasma concentration-time data from He et al. [14].

$* * * *$ Shi et al [2] , $K_{\mathrm{m}}=187 \mu \mathrm{m}$ and $V_{\max }=114 \mathrm{nmol} / \mathrm{mg} / \mathrm{min}$ in this paper, the final $V_{\max }$ was calculated with $70 \mathrm{~kg}$ BW, $1.8 \mathrm{~kg}$ of liver weight and $52.5 \mathrm{mg}$ microsomes/gram of liver for a standard human adult. NA: no result. 
Tissue/plasma partition coefficients. These were estimated by applying the area method of Gallo et al. [29] to the experimental data of rats after receiving a single oral dose of $10 \mathrm{mg} / \mathrm{kg}$ OP (Table 1). Briefly, the experimental OP/OC concentration-time curves in the plasma and organ/tissue were analyzed separately with the non-compartmental approach (WinNonlin ${ }^{\circledR}$, Scientific Consulting, Inc. Version 1.5 ) to obtain the area under the concentration-time curve (AUC). The in vivo tissue/plasma partition coefficient for a specific organ was estimated from the $A \cup C_{\text {tissue }} / A \cup C_{\text {plasma }}$ ratio, Table 1 , lists the final tissue/plasma partitioning coefficients which had been adjusted to available experimental data. In rat, plasma protein binding for OP was reported to be $53.7 \%$ [30], similar binding capacity in blood as in plasma was found in our study for both OP and OC. The tissue/plasma partition coefficients basically agreed with the lipid contents of the tissues and the lipid solubility of OP or OC.

Model simulation. The differential and algebraic equations describing the movement of OP and OC through the rat or human were formulated as a computer program. Mass balance differential equations for the model and the definition of the algebraic terms are given as parts of the model structure (Fig. 1 and Appendix). After incorporating the parameter values (Tables 1 and 2) into the model (Fig. 1), the differential and algebraic equations were solved numerically with the aid of AcsIXtreme ${ }^{\circledR}$ 2.4.2.1 (Aegis Technologies Group, Inc., Huntsville, AL). An i.v. injection function instead of oral absorption was used to drive the model when OP/OC was administered intravenously [31].

Scaling up of rat PBPK models to humans. The rat model (Fig. 2) was scaled up to humans by replacing the physiological parameters and pharmacokinetic parameters in the rat model with human specific values (Table 1). The human PBPK model was parameterized as follows: (a) tissue volumes and blood flows to tissues were taken from the literature $[25,26]$, (b) tissue/plasma partitioning coefficients were assumed to be the same as those of rats, (c) $F$ was set to $75 \%$ based on the absolute bioavailability reported in humans [14,32], (d) plasma protein binding of OC and OP in humans was $3 \%$ and $43 \%$, respectively [4], (d) gut content volumes was scaled based on the body weights of rats and humans; the gut content of a $70 \mathrm{~kg}$ human was determined to be $0.16 \mathrm{~L}$ [26], (e) clearance of $\mathrm{OC}\left(\mathrm{Cl}_{\mathrm{c}}\right)$ in urine was reported to be $18 \mathrm{~L} / \mathrm{h}$ $[14,33]$. Clearance value for $\mathrm{OP}\left(\mathrm{Cl}_{\mathrm{p}}\right)$ was scaled from the clearance of rats using the allometric equation, $\mathrm{CL}_{\mathrm{bc}}=\mathrm{CL}_{\mathrm{b}} /(\mathrm{BW})^{0.66}[34]$ initially, it was reported to be $20 \mathrm{~L} / \mathrm{h}$ while $\mathrm{CL} / F$ was $0.438 \mathrm{~L} / \mathrm{min}$ [14], considering the uncertainty of absorption parameters and the difference between classical model and PBPK model, $\mathrm{Cl}_{\mathrm{p}}$ was allowed to be optimized using the plasma concentration-time curve reported by He et al. [14], (f) in vitro $K_{\mathrm{m}}$ and $V_{\max }$ of OP metabolism in human liver microsomal incubates were reported to be $187 \mu \mathrm{M}$ and $114 \mathrm{nmol} / \mathrm{mg} / \mathrm{min}$, respectively [2]; these translated into in vivo $K_{\mathrm{m}}$ and $V_{\max }$ values of $76 \mathrm{mg} / \mathrm{L}$ and about $2.6 \times 10^{5} \mathrm{mg} / \mathrm{h}$, respectively for humans based on an average microsomal yield of $52.5 \mathrm{mg}$ microsomal proteins per g liver $[14,31,35]$, and (g) $k_{\mathrm{a}}$ and $k_{\mathrm{f}}$ rate constants (Table 2 ) were scaled up from rats using the equation, $k_{\mathrm{c}}=k_{\mathrm{a}} /(\mathrm{BW})^{-0.3}$, where $k_{\mathrm{a}}$ represented the rate constant, $k_{\mathrm{c}}$ represented the scaling coefficient and BW was the average body weight of human volunteers [36]. Model parameters that could not be parameterized a priori were optimized by fitting the PBPK model to available experimental data (see Data fitting below). Final parameter values used to implement the human PBPK model are listed in Table 3.

Data fitting and parameter optimization. The parameters that could not be obtained a priori or determined accurately were optimized by fitting the PBPK model to available data. Optimization was accomplished by minimizing the squared differences between model prediction and the experimental data using the maximized log likelihood function of the AcsIXtreme ${ }^{\circledR}$ OptStat program (Aegis Technologies Group, Inc., Huntsville, AL). Only the parameters that needed to be parameterized were varied, the values of other parameters in Tables 1 and 2 were kept constant. 
Table 3. Normalized sensitivity coefficients for OC concentrations in the lung and the plasma based on the simulated data of administering $10 \mathrm{mg} / \mathrm{kg}$ OP p.o. to the rat*

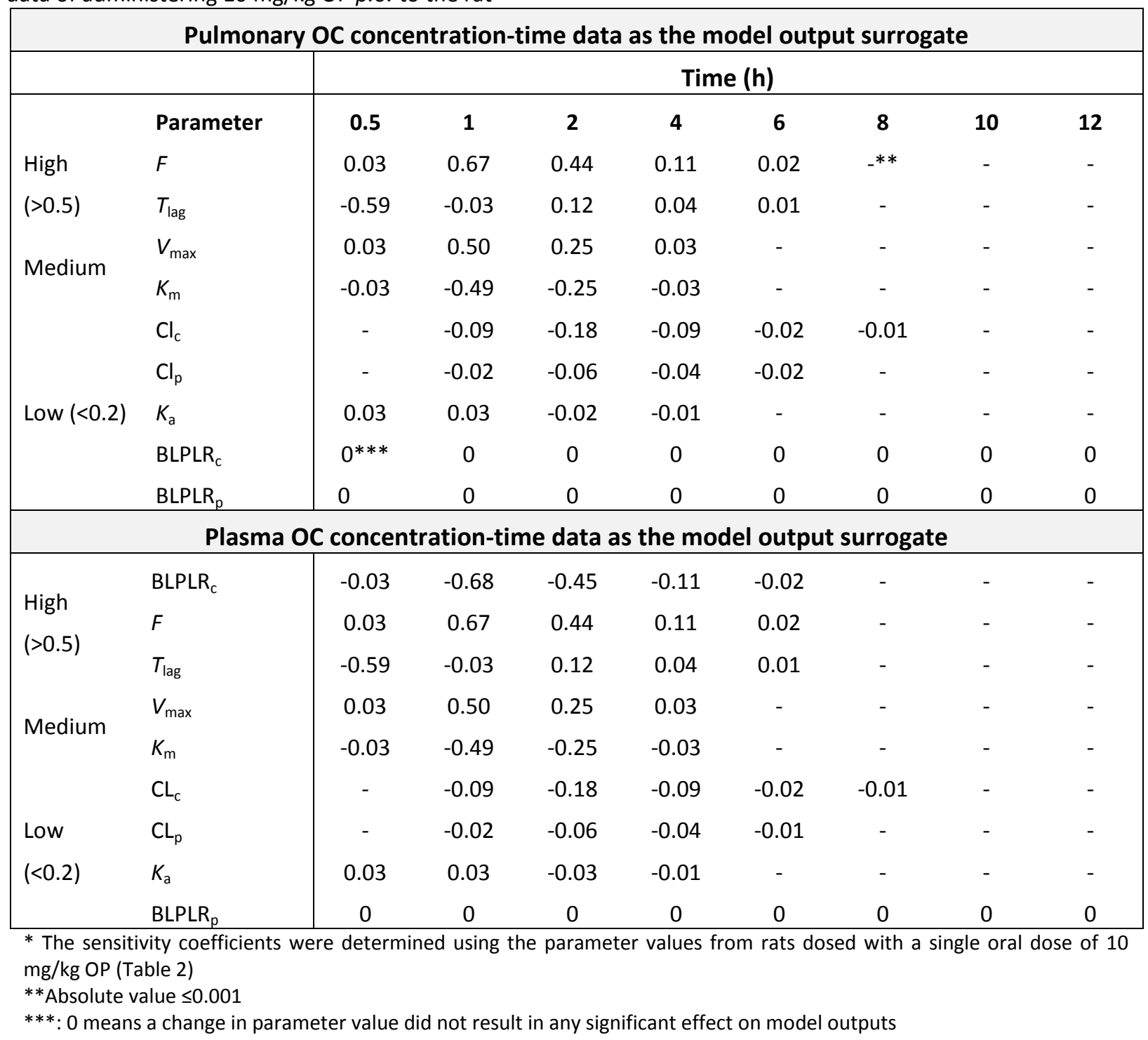

Validation and calibration of PBPK model. The PBPK models of rats and humans were validated or calibrated by comparing model-simulated results with experimental data not used in model development. The empirical data were obtained either from our own laboratories or from the literature. Because we were unable to obtain the original concentration-time data from the literature, they were read digitally from the publications using DigiMatic ${ }^{\circledR}$ (Windows version 2.2c, FEB Software, Chesterfield, Virginia).

The PBPK model was assumed to be validated if model simulation described closely the experimental data. Thus, the rat PBPK model was validated using the experimental data from rats dosed with a single oral dose of $50 \mathrm{mg} / \mathrm{kg}$ OP. The rat model was further validated using the plasma concentration-time data from rats after receiving a single oral dose of $30 \mathrm{mg} / \mathrm{kg}$ OP or an i.v. infusion of $30 \mathrm{mg} / \mathrm{kg} \mathrm{OC} \mathrm{[37].} \mathrm{Similarly,}$ the human PBPK model was calibrated using the datasets reported by He et al. [14] for human volunteers dosed with a single oral dose of $150 \mathrm{mg}$ OP or an i.v. infusion of $150 \mathrm{mg} \mathrm{OC}$. The human model was further validated based on the experimental data of humans receiving multiple oral doses of 50, 100, 200 or 500 $\mathrm{mg}$ of OP b.i.d. for one week.

Statistical and sensitivity analyses. Mean absolute prediction error (MAPE) was used as a measure of good fit between model-predicted concentration $\left(C_{\text {predi }}\right)$ and experimental concentration $\left(C_{\text {expti }}\right)$. It was 
calculated using the following equation:

$$
\operatorname{MAPE}(\%)=(100 / N)\left(\sum_{i=1}^{n}\left|C_{\text {expti }}-C_{\text {predi }}\right| / C_{\text {expti }}\right)
$$

where, i represents individual data points; $N$ is the total number of data points. A deviation within a factor of two between predicted and experimental concentration data (i.e., $\mathrm{MAPE}<50 \%$ ) was used as the criteria for goodness of fit [38].

Log-normalized sensitivity parameter (LSP) was used to identify key model parameters that had significant impacts on model prediction. LSP was defined as the partial derivatives of model response to the corresponding model parameter [39]:

$$
\mathrm{LSP}=\partial \ln R / \partial \ln X
$$

where $R$ is the model output and $X$ is the parameter for which the sensitivity is assessed. The sensitivity analysis was conducted by AcsIXtreme 2.0.1.2 (Aegis Technologies Group, Inc., Huntsville, AL) using the central difference method. The LSP represented the percentage change in an output value associated with the percentage change in the input parameter. The plasma and lung OC concentrations were chosen as the target tissues for model responses following oral administration of $10 \mathrm{mg} / \mathrm{kg}$ of $\mathrm{OP}$ to rats. Model parameters were changed individually by $0.1 \%$ to assess their impact on model prediction of plasma and lung concentrations. For each model response, magnitude, time dependency, and the mathematical sign of each sensitivity coefficient were examined. The ranking of effects of input parameters on the model prediction was based on the absolute magnitude of the sensitivity coefficient at the time [40]. Generally, the parameters that have large absolute sensitivity coefficients often cause sensitive model outputs in response to a small change in their values because they have a high probability for prediction error to occur due to inaccuracy of the parameter values.

\section{Results}

\section{Development and validation of rat PBPK model}

Table 2 summarizes the final parameter values used to implement the rat and human PBPK models. The oral bioavailability factor $(F)$ of OP was about $80 \%$ for both rats and humans. Plasma OP clearances $\left(\mathrm{CL}_{p}\right)$ for humans and rats were $100 \mathrm{~L} / \mathrm{h}$ and $0.4 \mathrm{~L} / \mathrm{h}$, respectively. If the $\mathrm{CL}_{\mathrm{p}}$ values were normalized by their respective body weights, the $\mathrm{CL}_{\mathrm{p}}$ of humans $(1.4 \mathrm{~L} / \mathrm{kg} / \mathrm{h})$ and rats $(1.6 \mathrm{~L} / \mathrm{kg} / \mathrm{h})$ were nearly identical. In contrast, plasma $\mathrm{OC}$ clearances $\left(\mathrm{CL}_{c}\right)$ of rats and humans were very different even after they were normalized by the body weight; the $\mathrm{CL}_{c}$ were $18 \mathrm{~L} / \mathrm{h}$ for $70 \mathrm{~kg} \mathrm{BW}$ human adult $(0.26 \mathrm{~L} / \mathrm{kg} / \mathrm{h})$ and $0.38 \mathrm{~L} / \mathrm{h}$ for $0.25 \mathrm{~kg} \mathrm{BW}$ rat $(1.5 \mathrm{~L} / \mathrm{kg} / \mathrm{h})$, respectively (Table 2$)$. The $K_{\mathrm{m}}$ and $V_{\max }$ values of OP biotransformation were $61.2 \mathrm{mg} / \mathrm{h}(245 \mathrm{mg} / \mathrm{kg} / \mathrm{h})$ and $300 \mathrm{mg} / \mathrm{L}$ for rats, and $2.6 \times 10^{5} \mathrm{mg} / \mathrm{h}(3714 \mathrm{mg} / \mathrm{kg} / \mathrm{h}$ for $70 \mathrm{~kg} \mathrm{BW})$ and $76 \mathrm{mg} / \mathrm{L}$ for humans.

\section{OP/OC concentration-time profiles in plasma/tissues of rats}

OP was metabolized primarily to OC in rats. Thus, mostly OC and occasionally low concentrations of OP were found in the plasma (Figs. 3 and 4) although both OP and OC were found in the major organs of rats. The $C_{\max }$ of OC in the plasma were 0.80 and $5.63 \mu \mathrm{g} / \mathrm{ml}$, respectively after receiving $10 \mathrm{mg} / \mathrm{kg}$ and $50 \mathrm{mg} / \mathrm{kg}$ of OP by the rat. It decreased in the order of liver > kidney > lung > plasma (Figs. 3 and 4). Although OP was found at a higher concentration than $\mathrm{OC}$ in the lung (Figs. 3 and 4) and spleen (data not shown), OP concentration was lower than OC concentration in kidney, liver (Figs. 3 and 4), and muscle (data not 
shown). The $A \cup C_{0-4 h}$ of $O C$ in the lungs were 5.2 and $26.1 \mu \mathrm{g} \cdot \mathrm{h} / \mathrm{ml}$, respectively when rats were treated with an oral dose of $10 \mathrm{mg} / \mathrm{kg}$ and $50 \mathrm{mg} / \mathrm{kg}$ OP. These results showed that the dose of OC delivered to the lungs increased in proportion to the OP dose applied externally, a finding which was consistent with the assumption of linear kinetics in the PBPK model.

(a) Liver

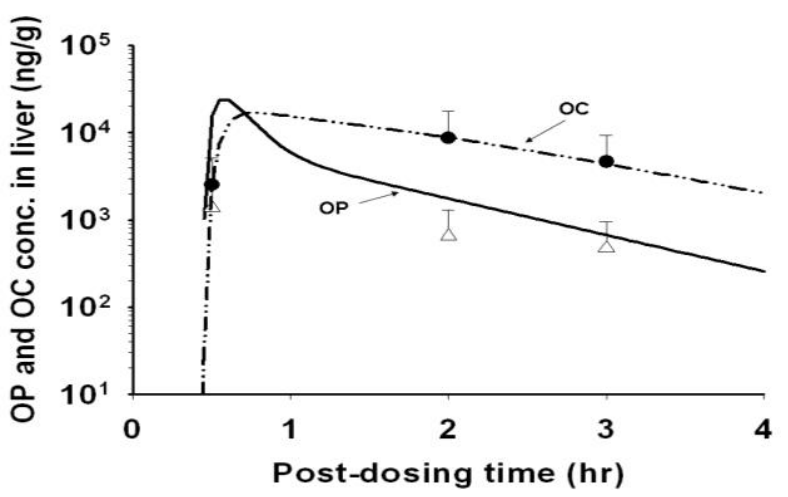

(c) Lung

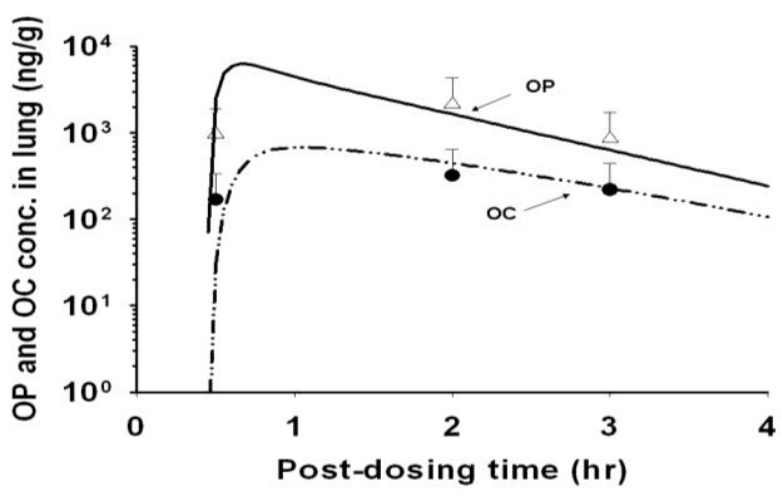

(e) Brain

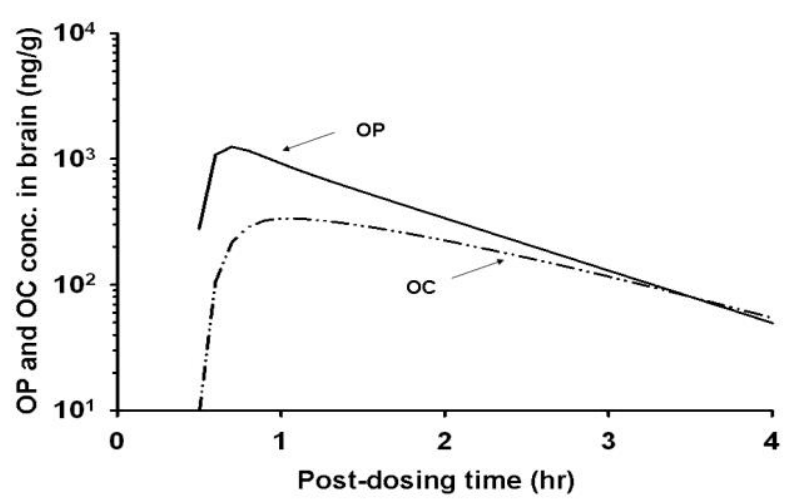

(b) Kidney

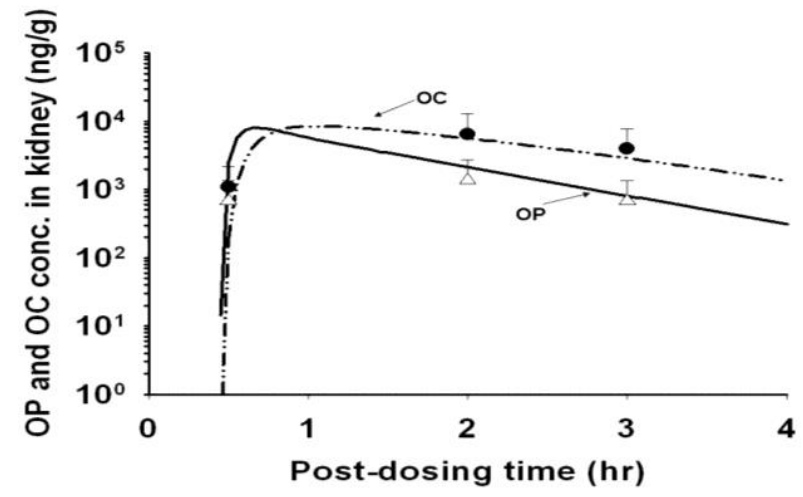

(d) Plasma

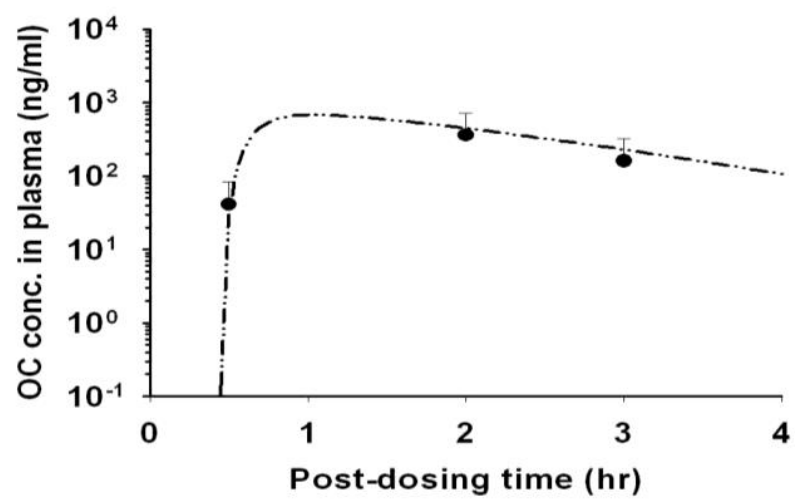

Figure 3. Time course of OP and $O C$ concentrations in the plasma and tissues of rats after administering a single oral dose of $10 \mathrm{mg} / \mathrm{kg}$ OP. (a) liver, (b) kidney, (c) lung, (d) plasma, (e) brain. Data points, means \pm S.D. of the experimental plasma/tissue concentrations from three different rats; $(-)$ model-simulated ${ }^{-} \mathrm{P}$ concentrations; (- - - ) model-simulated OC concentrations 
(a) Liver

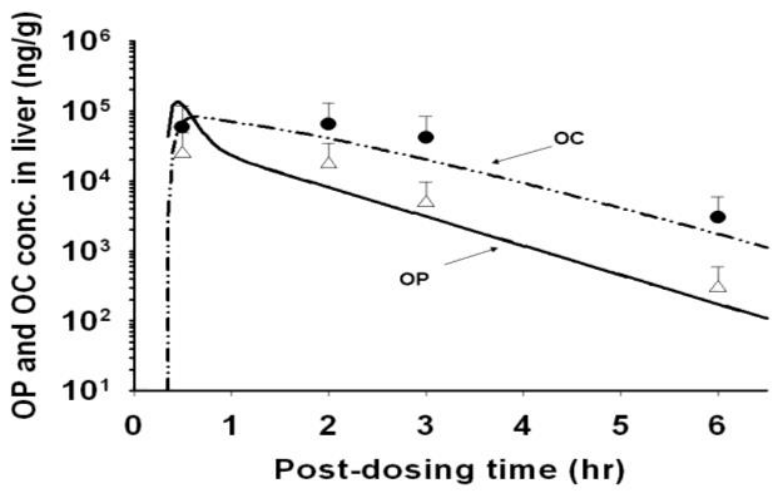

(c) Lung

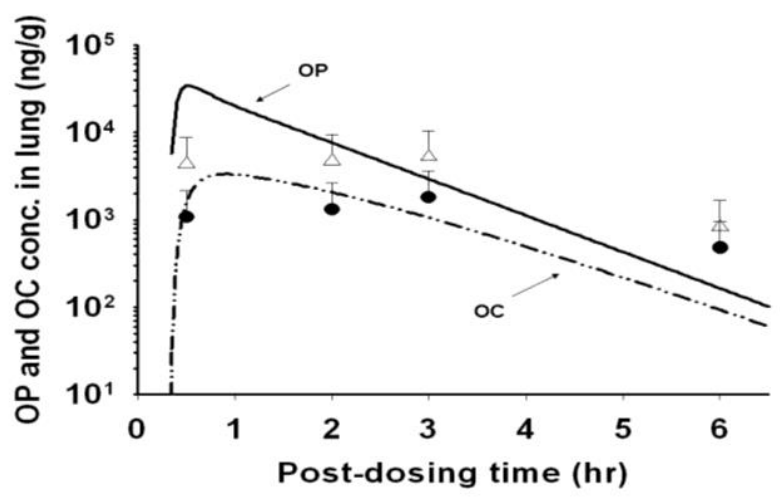

(e) Brain

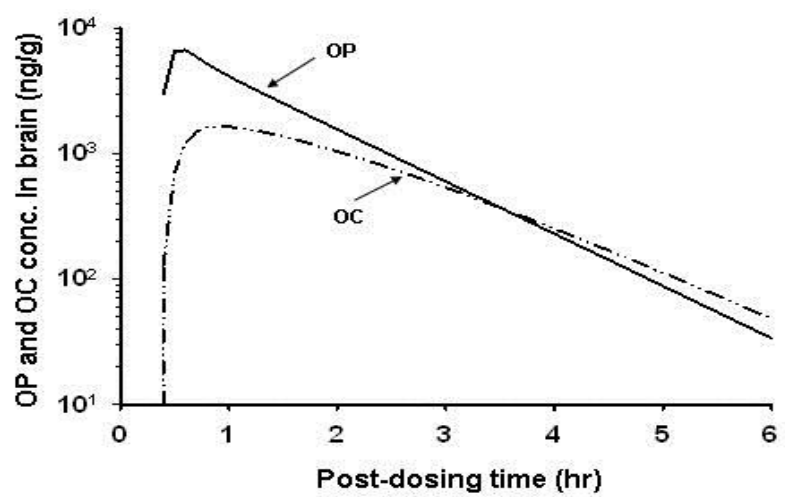

(b) Kidney

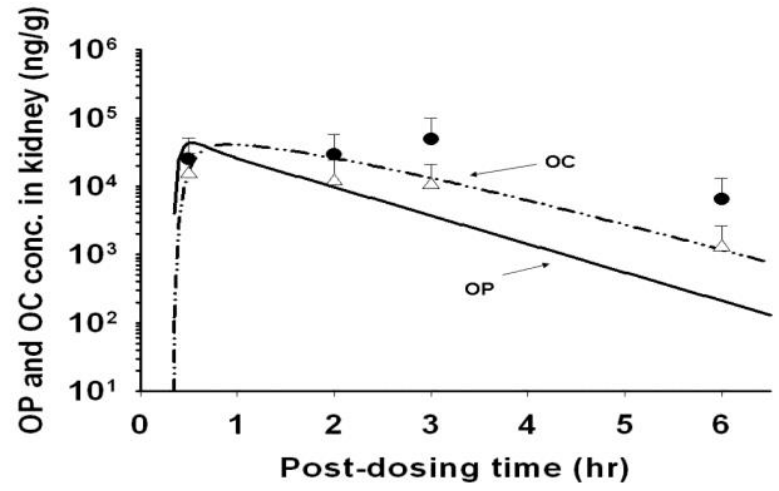

(d) Plasma

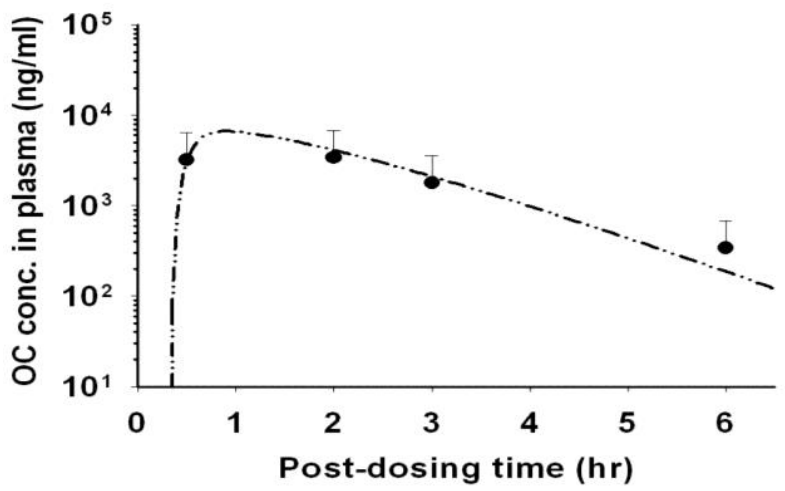

Figure 4. Time course of $\mathrm{OP}$ and $\mathrm{OC}$ concentrations in the plasma and tissues of rats after administering a single oral dose of $50 \mathrm{mg} / \mathrm{kg}$ OP. (a) liver, (b) kidney, (c) lung, (d) plasma, (e) brain. Data points, means \pm S.D. of the experimental plasma/tissue concentrations from three different rats; (-) model-simulated OP concentrations; (- - - ) model-simulated OC concentrations

The rat PBPK model was developed based on the experimental data of the $10 \mathrm{mg} / \mathrm{kg}$ treated rats (Fig. 3). It was subsequently validated using the experimental data of the $50 \mathrm{mg} / \mathrm{kg}$ treated rats (Fig. 4). In order to fit the experimental data well, however, the $K_{\mathrm{a}}$ and $F$ values of the PBPK model for the $50 \mathrm{mg} / \mathrm{kg}$ treated rats had to be higher than those of the $10 \mathrm{mg} / \mathrm{kg}$ treated rats, suggesting that OP absorption was more rapid and extensive in the $50 \mathrm{mg} / \mathrm{kg}$ treated rats than the $10 \mathrm{mg} / \mathrm{kg}$ treated rats (Table 2). The rat PBPK model was also validated using the plasma OC concentration-time data reported by Eisenberg et al. [37]. The rat PBPK model was able to predict accurately the experimental data (Fig. 5) and the tissue distribution data of the $10 \mathrm{mg} / \mathrm{kg}$-treated (Fig. 3) and $50 \mathrm{mg} / \mathrm{kg}$-treated rats (Fig. 4). The PBPK model also was used to simulate the kinetic profiles of OP/OC in the rat's brain (Figs. 3e and 4e). For rats dosed with $10 \mathrm{mg} / \mathrm{kg} \mathrm{OP}$, 
the predicted $C_{\max }$ for OP and OC in the brain were $1.25 \mu \mathrm{g} / \mathrm{g}$ and $0.34 \mu \mathrm{g} / \mathrm{g}$, respectively. For rats dosed with $50 \mathrm{mg} / \mathrm{kg} \mathrm{OP}$, the predicted $C_{\max }$ for OP and OC were $6.64 \mu \mathrm{g} / \mathrm{g}$ and $1.65 \mu \mathrm{g} / \mathrm{g}$, respectively. These results were in agreement with the other rat tissue/organs in which OP/OC tissue doses were found to increase linearly with the applied OP dose (Figs. 3 and 4). We also performed route-to-route extrapolation by comparing model simulation with the experimental data reported by Eisenberg et al. [37]. The PBPK model was able to describe closely the plasma OP/OC concentration-time profiles of rats receiving either a single dose of $30 \mathrm{mg} / \mathrm{kg}$ OP orally or an i.v. infusion of $30 \mathrm{mg} / \mathrm{kg} \mathrm{OC} \mathrm{(Fig.} \mathrm{5).}$

\section{Sensitivity analysis of rat PBPK model}

The sensitivity analysis provided a quantitative means to evaluate how the various input parameters might affect the $O C$ dose metrics in the lungs and plasma when the rats were treated with a single dose of $10 \mathrm{mg} / \mathrm{kg}$ OP orally. Table 3 shows a summary of the sensitivity analysis results. The sensitivity coefficients were a mix of positive and negative values which varied with time over the $12 \mathrm{~h}$ post-dosing period. We arbitrarily grouped the parameters into 3 different categories according to their absolute sensitivity coefficients: high (>0.5), medium (0.2-0.5), and low $(<0.2)$. Based on these groupings, $F$ and $T_{\text {lag }}$ were classified as high impact parameters, $K_{\mathrm{m}}$ and $V_{\max }$ were classified as medium impact parameters, and $\mathrm{CL}_{c}$, $\mathrm{CL}_{\mathrm{p}}, K_{\mathrm{a}}$ and $\mathrm{BLPLR}_{\mathrm{p}}$ were classified as low impact parameters for the simulated OC dose metrics in the plasma and lungs. Interestingly, BLPLR $\mathrm{c}$ had a high impact on the plasma dose metric but a low impact on the pulmonary dose metric. Because the $F$ value was positive over the $12 \mathrm{~h}$ post-dosing period, OC concentrations in the lung and plasma would increase with an increasing $F$ value. Because both of the $\mathrm{CL}_{c}$ and $\mathrm{CL}_{p}$ sensitivity coefficients had negative values, $\mathrm{OC}$ concentrations in the lung and plasma would decrease with increasing $\mathrm{CL}_{c}$ and $\mathrm{CL}_{p}$ values.

(a) p.o. administration

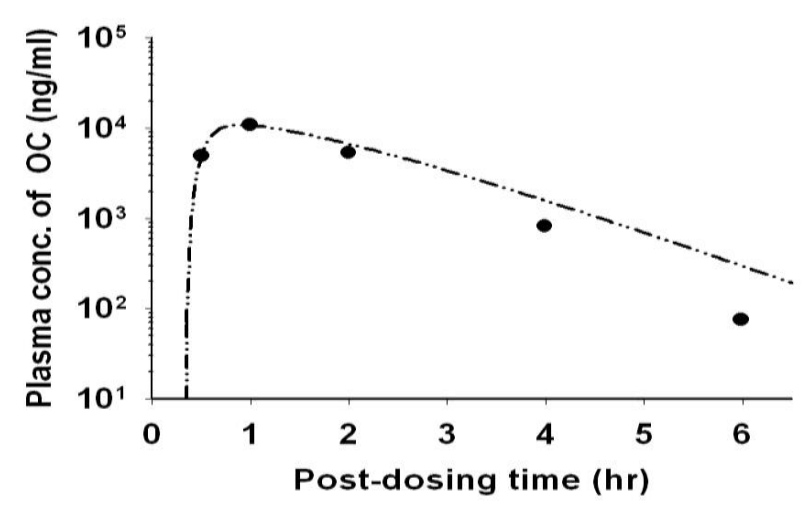

(b) i.v. injection

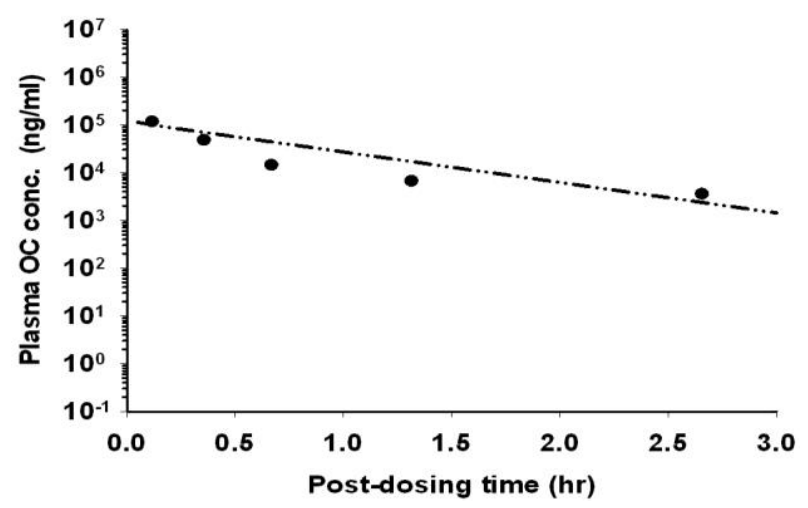

Figure 5. Plasma OC concentration-time profiles in rats after administering (a) a single oral dose of $30 \mathrm{mg} / \mathrm{g}$ $\mathrm{OP}$, (b) an i.v. injection of $30 \mathrm{mg} / \mathrm{kg}$ OC. Data points, means \pm S.D. of the experimental plasma/tissue concentrations. (- - - ) model-simulated OC concentrations. Experimental data were adapted from Eisenberg et al. [37]

\section{Calibration of the human PBPK model}

The human PBPK model was calibrated using the plasma concentration-time data from humans receiving either a single oral dose of $150 \mathrm{mg}$ OP or an i.v. infusion of $150 \mathrm{mg}$ OC [14]. Fig. 6 shows the observed concentrations together with the simulated concentrations for humans after p.o. administration of OP. Fig. 7 shows the model simulation and the experimental concentration-time profiles of plasma OC in humans during and after a 3-hour i.v. infusion of $150 \mathrm{mg} O C$. The PBPK model was able to describe the experimental data for both administration routes reasonably well. The optimized $F$ value for human model 
was 0.75 (Table 2) which showed extensive absorption of orally administered OP. Simulated $C_{\max }$ for OP and $\mathrm{OC}$ in the plasma was 0.08 and $0.44 \mu \mathrm{g} / \mathrm{ml}$, respectively, after dosing humans with $150 \mathrm{mg} \mathrm{OP}$ orally (Fig.6). The time to reach peak plasma concentration ( $\left.T_{\max }\right)$ for OP and OC was 1 and $4 \mathrm{~h}$, respectively. These results indicated that $O C$ could remain in the plasma for a longer period than OP. Following oral administration of OP, plasma OC concentrations in humans were always $>40 \mathrm{ng} / \mathrm{ml}$ after the initial absorption phase (Fig. 6), which was much higher than the minimum $\mathrm{IC}_{50}$ of neuraminidase inhibition levels $(3-10 \mathrm{ng} / \mathrm{ml})$ reported previously by Davies [26].

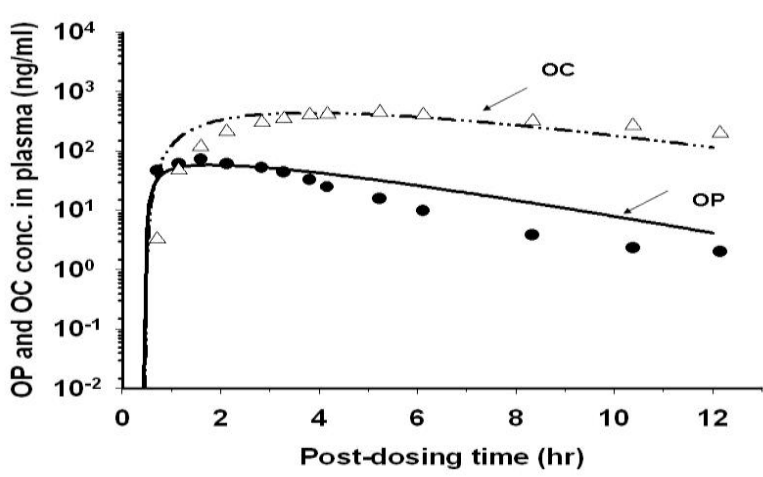

Figure 6. Typical OP and OC concentration-time profiles in the plasma of human volunteers receiving an oral dose of $150 \mathrm{mg}$ OP. Data points represent means \pm S.D. of the experimental data which are adapted from He et al., [14]. (-) model-simulated OP concentrations; (- - - - ) model-simulated OC concentrations

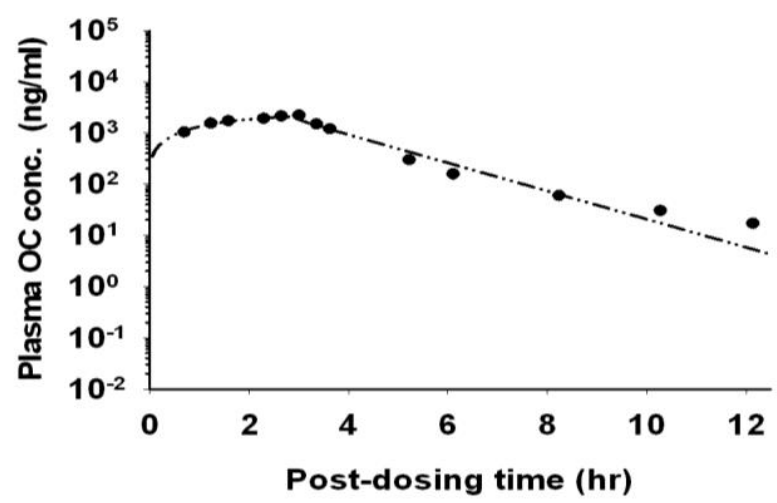

Figure 7. A typical OC concentration-time profile in the plasma of human volunteers receiving an i.v. infusion of $150 \mathrm{mg} \mathrm{OC}$. Data points represent means + S.D. of the experimental data which are adapted from He et al., [14]. (- - - ) modelsimulated OC concentrations

\section{Prediction of tissue/plasma OP/OC concentrations in humans receiving multiple OP dose regimens}

The PBPK model was used to simulate the kinetics of plasma $O C$ in humans after receiving multiple oral dose regimens of OP [14]. In their studies, the human volunteers were dosed with 50, 100, 200 and $500 \mathrm{mg}$ OP b.i.d. for 6 days. The model-predicted $C_{\max } / C_{\min }$ ratios for OC in the plasma were $3.5(218 \mathrm{ng} / \mathrm{ml}: 62$ $\mathrm{ng} / \mathrm{ml}), 2.5(400 \mathrm{ng} / \mathrm{ml}: 158 \mathrm{ng} / \mathrm{ml}), 3.0(838 \mathrm{ng} / \mathrm{ml}: 279 \mathrm{ng} / \mathrm{ml})$ and $1.9(1846 \mathrm{ng} / \mathrm{ml}: 959 \mathrm{ng} / \mathrm{ml})$, respectively (Fig. 8). The $C_{\max } / C_{\min }$ ratio decreases with an increasing external OP dose except for the $100 \mathrm{mg}$ b.i.d dose, which indicates less OC concentration fluctuation in the plasma at a higher OP dose. In addition, the PBPK model was used to predict the internal tissue dose of $\mathrm{OC}$ in the brain and the lung of these studies. The steady-state OC doses/concentrations predicted for the lungs and brain were found to be lower than that of the plasma. When the dose metrics of $\mathrm{OC}$ were expressed in $\mathrm{AUC}_{0-6 \mathrm{day}}$, they were $21.4,42.5,85.3$ and $210.2 \mu \mathrm{g} / \mathrm{ml} \cdot \mathrm{h}$, respectively, for the 50, 100, 200, and $500 \mathrm{mg}$ doses. The corresponding $\mathrm{OC}$ dose metrics for the lungs were 10.7, 21.2, 42.6, $105.0 \mu \mathrm{g} / \mathrm{ml} \cdot \mathrm{h}$, respectively. For the brain, they were $5.3,10.6,21.3,52.5 \mathrm{\mu g} / \mathrm{ml} \cdot \mathrm{h}$, respectively. Thus, the dose metrics of $\mathrm{OC}$ in these organs/tissues generally decrease in the order of plasma > lung > brain although they were all linearly related to the externally applied OP dose. 


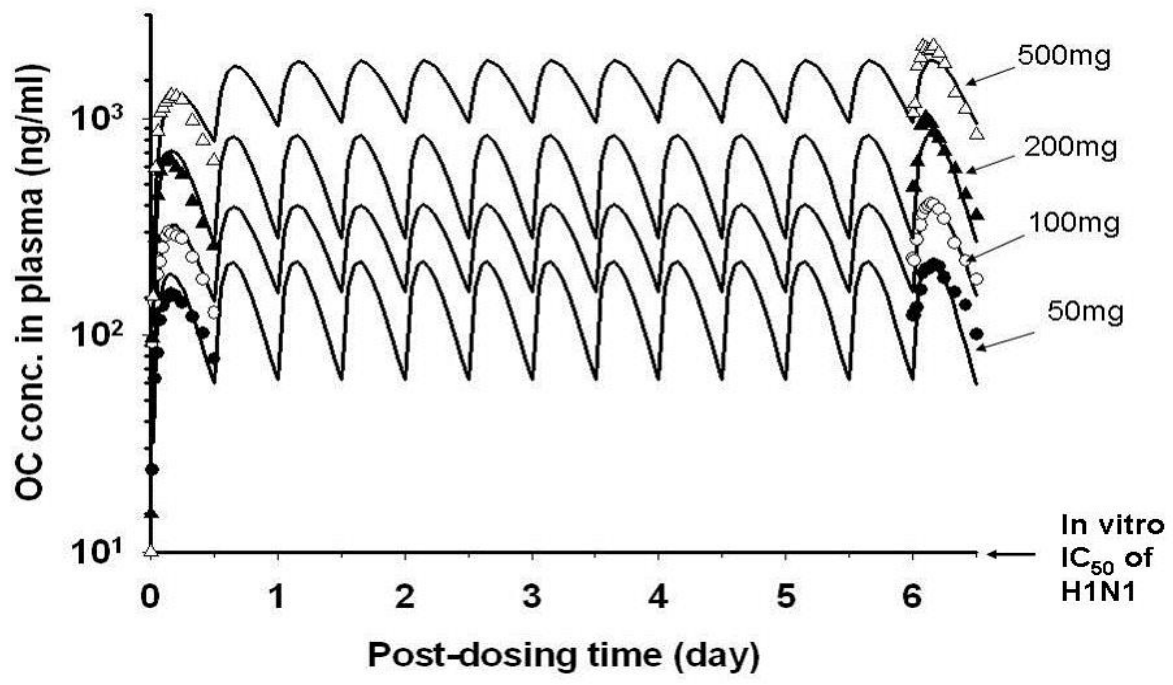

Figure 8. Plasma OC concentration-time profiles in human volunteers receiving multiple oral dose regimens of 50, 100, 200 or $500 \mathrm{mg}$ OP b.i.d. for 6 days. Data points represent means \pm S.D. of the experimental plasma OC concentrations which are adapted from He et al, (17). (-) model-simulated OC concentrations

We have also used the human PBPK model to simulate OC (Fig. 9) and OP (Fig. 10) dose metrics in a hypothetical human after receiving the recommended dose regimen of $75 \mathrm{mg}$ OP b.i.d. for 6 days. Fig. 9 shows the simulated $\mathrm{OC}$ concentrations in the plasma and major organs, which decreases in the order of liver $>$ kidney $>$ plasma $\approx$ the rest of body $>$ lung $>$ brain $\approx$ fat. The mean OC concentrations predicted for the lung and brain were $\geq 0.052 \mu \mathrm{g} / \mathrm{g}$ and $\geq 0.026 \mu \mathrm{g} / \mathrm{g}$, respectively. Fig 10 shows the simulated OP concentrations in the human plasma/organs which decreased in the order of liver $>$ lung $>$ kidney $>$ the rest of body $>$ muscle $\approx$ spleen $>$ plasma $>$ brain $\approx$ fat. The predicted mean OP concentrations in the gut was high $(3.72 \mu \mathrm{g} / \mathrm{g})$ indicating a significant amount of OP was not absorbed.

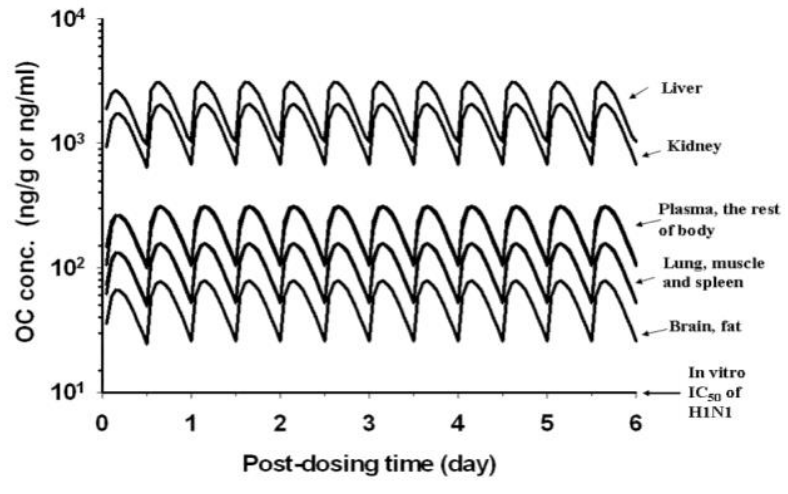

Figure 9. Simulated OC concentration-time profiles in the plasma and tissues of a hypothetical 70-kg human receiving $75 \mathrm{mg}$ OP b.i.d. for 6 days. (-) model-simulated OC concentrations

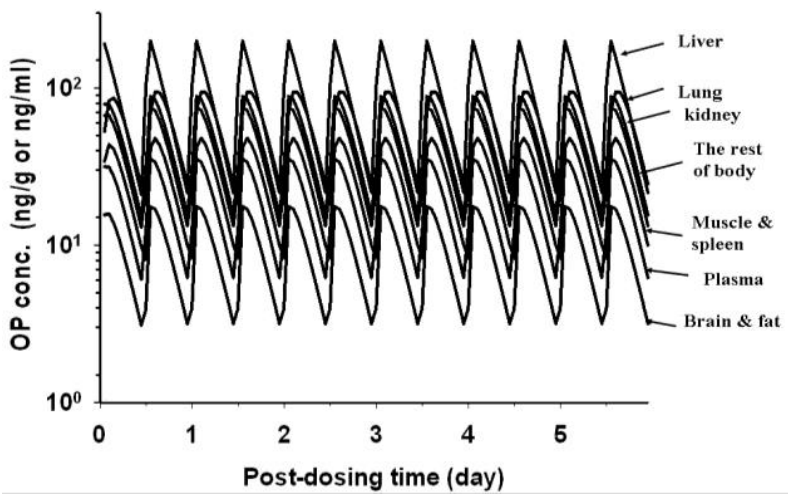

Figure 10. Simulated OP concentration-time profiles in the plasma and tissues of a hypothetical 70-kg human receiving $75 \mathrm{mg}$ OP b.i.d. for 6 days (-) model-simulated OP concentrations

\section{Discussion}

Previous studies have shown rats and humans metabolize OP differently under in vitro incubation conditions; $\mathrm{OP}$ is hydrolyzed primarily to $\mathrm{OC}$ by the carboxylesterases in rat plasma but is not hydrolysed by the carboxylesterases in human plasma [23]. Also, OP is metabolized by the hepatic CYP450 system of rats to minor metabolites [13]. In contrast, although $\mathrm{OP}$ is metabolized to $\mathrm{OC}$ by the hepatic carboxylesterases in humans, the CYP450 system does not seem to involve in its biotransformation [14].Thus, although OP 
and OC are found in the plasma of humans after administering OP orally [14,32], only OC and occasionally $\mathrm{OP}$ are detected in the plasma of rats (Figs. 3 and 4). The species difference in OP metabolism may be related to the different types of carboxylesterases in rats and humans [41]. As a result, not all systemic OP in humans are converted to $O C$ by the hepatic carboxylesterases [14,32].

Results of our study show the kinetics of in vitro OP biotransformation in rat plasma can be adequately described by the Michaelis-Menten equation (Table 2). Because carboxylesterase activity varies among different animal species and organ sites [41], OP biotransformation is assumed to take place only in the liver of rats during PBPK model development (Fig. 2) although the $K_{\mathrm{m}}(300 \mathrm{mg} / \mathrm{L})$ and $V_{\max }(61.2 \mathrm{mg} / \mathrm{h})$ of the rat PBPK model have been derived from rat plasma incubation studies. In contrast, the $K_{\mathrm{m}}(187 \mu \mathrm{M}$, $76 \mathrm{mg} / \mathrm{L})$ and $V_{\max }\left(114 \mathrm{nmol} / \mathrm{mg} / \mathrm{min}, 2.6 \times 10^{5} \mathrm{mg} / \mathrm{h}\right)$ of the human PBPK model have been obtained from in vitro human liver microsomal studies of Shi et al., [2] (Table 2).

Our studies also show that the $C_{\max }$ of OC in the organs/tissues of rats decreases in the order of liver > kidney $>$ lung $>$ plasma $>$ brain. Similar orders of radioactivity distribution were observed in the ferrets [14] and mice [15] after oral administration of radiolabeled OP. However, because the radioactivity is comprised of a mixture of $O P, O C$ and other metabolites, it is not possible to quantify OP and OC individually based on the results of the tissue distribution studies.

Our PBPK model provides a means to integrate relevant in vitro and in vivo data into a coherent description of OP/OC pharmacokinetics for the whole animal. The model is comprised of an OP and an OC sub-models (Fig. 2). Model performance is evaluated by comparing simulation results with experimental data. The proposed PBPK model is quite complex but can be collapsed into a less complex model by consolidating the various tissues/organs into rich and poor perfusion compartments. We have chosen a more complex model for the present study because it possesses the structural details to address the pharmacological and toxicological effects of OP in humans. In addition, although it is more difficult to fit available experimental data to a complex model, the derived parameter values from a complex model are more accurate than those derived from a less complex model [19].

More than 80 parameter values are required to implement the PBPK model of OP/OC. There is always uncertainty regarding whether they actually represent true parameter values. We have used the analytical sensitivity analysis [39] to identify the model parameters that significantly affect the OC dose metrics in the lungs and plasma. As shown in Table 3, none of the parameter has an absolute sensitivity coefficient significantly greater than 1.0. This indicates that there is no amplification of errors from the input parameters in the prediction of OC dose metrics in these target organs. In other words, the OC dose metrics in the lungs and plasma are predicted with a certain degree of confidence even though some of the model parameter values may have been determined inaccurately.

The PBPK model in rat was developed majorly with the dataset following orally administered $10 \mathrm{mg} / \mathrm{kg}$, among all the parameters, distribution, metabolism and elimination parameters were basically from experimental data while absorption related parameters were allowed to be optimized to a certain extent, the model could predict the tissue distributions satisfactorily for $10 \mathrm{mg} / \mathrm{kg}$ and two published rat plasma datasets $[15,16]$. While the developed model was used to simulate the tissue exposure in rat following orally administered $50 \mathrm{mg} / \mathrm{kg}$ for validation, the simulations seemed to have the tendency of overestimating $C_{\max }$ and underestimating $A U C$ for both OP and OC in kidney and lung, the discrepancy might be related to the higher optimized parameters related to absorption $\left(K_{\mathrm{a}}, F\right)$ and renal clearance of OP $\left(\mathrm{CL}_{\mathrm{p}}\right)$ compared to the reported values. Considering the satisfactory simulations for exposure at $10 \mathrm{mg} / \mathrm{kg}$ 
and the uncertainty of absorption processes, this leaves space for further refinement or validation. On the other hand, the current PBPK model will be definitely improved with further specific parameters for metabolism considering different enzymes and happening sites between human and rat, absorption/distribution parameters related to P-GP transporters (brain/GI tract) [42-44] and elimination parameters related to organic anion transporters (OAT) in kidney [45].

The therapeutic effects of OP in humans are related to the inhibition of neuraminidase activity of the influenza virus. In other words, inhibition of neuraminidase activity by OC will result in a decrease or even stoppage of progeny virion release and propagation in the respiratory tract. Thus OP efficacy may be evaluated by comparing the dosimetry of $\mathrm{OC}$ in the lung and the $\mathrm{IC}_{50}$ of $\mathrm{OC}$ of neuraminidases. He et al., [14] showed that the $\mathrm{IC}_{50}$ of $\mathrm{OC}$ for neuraminidases range from $0.3-2.0 \mathrm{nM}(0.08-0.28 \mathrm{ng} / \mathrm{ml})$ in an enzymatic assay to $0.6-155 \mathrm{nM}(0.17-32.8 \mathrm{ng} / \mathrm{ml})$ in a viral replication inhibition assay. As such the $\mathrm{IC}_{50}$ of OC differs among the subtype of influenza virus neuraminidases; it may range from 0.01-3.3 nM and 0.7$2.2 \mathrm{nM}$ for H2N3 and H1N1 influenza viruses, respectively [32]. As shown in Fig. 9, the steady-state concentrations of $\mathrm{OC}$ in the plasma/organs of a hypothetical human receiving the recommended OP dose regimen are much higher than the minimum of in vitro $\mathrm{IC}_{50}$ of $\mathrm{H} 1 \mathrm{~N} 1$ virus neuraminidase $(3-10 \mathrm{ng} / \mathrm{ml})$ [14]. Also, the trough $\left(C_{\min }\right)$ of the OC concentration-time curve in the lung is more than 10 fold higher than the $\mathrm{IC}_{50}$ value (Fig. 9). As such, OP is an effective anti-viral drug for H1N1 virus and perhaps, for other influenza virus strains as well [32]. The dosimetry of $O C$ in the lung also explains why a dose regimen higher than 75 $\mathrm{mg}$ OP b.i.d. for one week would not increase the efficacy of OP significantly [3, 4]. As shown above, pulmonary OC concentration already is much higher than the minimum of in vitro $\mathrm{IC}_{50}$. Thus, a dose regimen higher than $75 \mathrm{mg}$ OP b.i.d. is unlikely to have additional inhibitory effects on neuraminidase activity.

The side effects of OP/OC also are explainable by the dose metrics of OP and OC in the brain and gastrointestinal tract; no threshold doses of toxicity have been reported in these organs. As shown in Fig. 8, modeled $O C A \cup C_{\text {brain }} / A \cup C_{\text {plasma }}$ ratios for humans dosed with 50, 100, 200, and $500 \mathrm{mg} O P$ are 5.34/21.4, 10.6/42.5, 21.3/85.3, and 52.5/210.2, respectively, (Fig.8) yielding a mean $O C A \cup C_{\text {brain }} / A \cup C_{\text {plasma }}$ ratio of about 0.25 . Jhee et al [42] have reported that the mean spinal fluid/plasma concentration ratio for OC in humans is $2.93 \pm 4.06$ which is about 10 -fold higher than the modeled $A \cup C_{\text {brain }} / A \cup C_{\text {plasma }}$ ratio observed in the present study. Other study reported the brain-to-plasma exposure ratios approximately 0.2 for OP and 0.01 for OC $[43,44]$, these result suggested significant variation between different studies. In our model, the brain/ plasma partition coefficients for OP and OC were 0.5 and 0.25 respectively. It is assumed that only a small amount of $\mathrm{OC}$ seems able to penetrate the blood-brain barrier to reach the brain tissue considering $\mathrm{OC}$ with high polarity and $\mathrm{OP}$ as the substrate of efflux transporter-P-glycoprotein. As such, $\mathrm{OP} / \mathrm{OC}$ probably is not the major cause of the observed neuropsychiatric effects in humans. As for the gastrointestinal side effects (e.g., abdominal pain, diarrhea, and nausea) [3,4], they may be related to the high levels of OP in the digestive system and contact site toxicity since OP concentrations in the gastrointestinal tract and liver may be as high as $3.72 \mu \mathrm{g} / \mathrm{g}$ and $2.00 \mu \mathrm{g} / \mathrm{g}$, respectively (Fig. 8).

This is the first study in which a PBPK model is used to predict the internal tissue doses of OP/OC in humans. The human and rat PBPK models are able to predict the pharmacokinetic behaviors and internal tissue doses of OP and OC accurately. Thus, the PBPK model is a valuable, quantitative tool for routerelated (Fig. 5), species-related (Fig. 6), and dose-related (Fig. 8) extrapolation. The proposed PBPK model has many practical applications: it can be used to assess the dosimetry of OP/OC in the internal tissues/organs of humans providing a more realistic and accurate account of the dose-response 
relationship of OP/OC than the externally applied dose. The PBPK model also is useful in adjusting the dose regimens for patients in disease states such as renal failure and liver damage [22].

Conflict of interest statement: There is no conflict of interest for this study.

\section{List of abbreviations}

PBPK model: physiologically-based pharmacokinetic model;

OP: oseltamivir phosphate;

OC: oseltamivir carboxylate;

$F$ : fraction of absorption or empirical bioavailability factor

$K_{\mathrm{a}}$ : absorption rate constant;

$T_{\text {lag: }}$ lag time for absorption

$\mathrm{CL}$ : whole body clearance;

$K_{\mathrm{m}}$ : Michaelis constant;

$V_{\text {max }}$ : maximum reaction rate;

$k_{\mathrm{f}}$ : the fecal excretion rate constant

QXY: blood flow to the organ;

CXY: OP/OC concentration in the organ;

VXY: volume of the organ;

RXY: tissue/plasma partition coefficient for the tissue;

BLPLR: blood and plasma concentration ratio for OP or OC

AUC: area under the time-concentration curve

BW: the average body weight of humans and rats.

Acknowledgements: The authors thank the RFCID/HHSRF/HSRF/HCPF in Hong Kong for financial support of this project, and Hoffman La-Roche for providing Tamiflu (both the pro-drug oseltamivir phosphate and the active metabolite oseltamivir carboxylate) for the project. The authors also thank Prof. Hei wun Leung and the CMA laboratory for their help in developing analytical methods for Tamiflu and its metabolite, and Dr. J.A. Raymond for reviewing the manuscript.

\section{References}

[1] J.R. Smith, C.R. Rayner, B. Donner, M. Wollenhaupt, K. Klumpp, R. Dutkowski. Oseltamivir in seasonal, pandemic, and avian influenza: a comprehensive review of 10-years clinical experience. Adv. Ther. 28(11) (2011) 927-959.

[2] D. Shi, J. Yang, D. Yang, E.L. LeCluyse, C. Black, L.You, F. Akhlaghi, B.Yan. Anti-influenza prodrug oseltamivir is activated by carboxylesterase human carboxylesterase 1 , and the activation is inhibited by antiplatelet agent clopidogrel. J. Pharmacol. Exp. Ther. 319 (2006) 1477-1484.

[3] F.G. Hayden, J.J. Treanor, R.S. Fritz, M. Lobo Betts, R.F. Miller, M.N. Kinnersley, R.G. Mills, P. Ward, S.E. Straus. Use of the oral neuraminidase inhibitor oseltamivir in experimental human influenza: randomized controlled trials for prevention and treatment. JAMA 282 (1999) 1240-1246.

[4] K.G. Nicholson, F.Y. Aoki, A.D. Osterhaus, S. Trottier, O. Carewicz, C.H. Mercier, A. Rode, N. Kinnersley, P Ward. Efficacy and safety of oseltamivir in treatment of acute influenza: a randomized controlled trial. Lancet 355 (2000) 1845-1850.

[5] FDA, http://www.fda.gov/medwatch/safety/, Safety Alerts for Human Medical Products (Drugs, Biologics, Medical Devices, Special Nutritionals, and Cosmetics). 2008/safety08.htm\# Tamiflu. Posted on March 4 [accessed 06.11.08]. 
[6] N. Goshima, T. Nakano, M. Nagao, T. Ihara. A clinical study of abnormal behaviors in patients with influenza. Infect. Immun Child 18 (2006) 371-376.

[7] S. Toovey, C. Rayner, E. Prinssen, T. Chu, B. Donner, B. Thakrar, R. Dutkowski, G. Hoffmann, A. Breidenbach, L. Lindemann, E. Carey, L. Boak, R. Gieschke, S. Sacks, J. Solsky, J. Small, D. Reddy. Assessment of neuropsychiatric adverse events in influenza patients treated with oseltamivir: a comprehensive review. Drug Safety 31 (2008) 1097-1114.

[8] K. Morimoto, M. Nakakariya, Y. Shirasaka, C. Kakinuma, T. Fujita, L. Tamai, T. Ogihara. Oseltamivir (Tamiflu) efflux transport at the blood-brain barrier via P-glycoprotein. Drug Metab. Dispos. 36 (2008) 6-9.

[9] G. Hoffmann, C. Funk, S. Fowler, M.B. Otteneder, A. Breidenbach, C.R. Rayner, T. Chu, E.P. Prinssen. Nonclinical pharmacokinetics of oseltamivir and oseltamivir carboxylate in the central nervous system, Antimicrob. Agents Chemother. 53 (2009) 753-4761

[10] S.M. Crain, K.F. Shen. Neuraminidase inhibitor ,oseltamivir blocks GM1 ganglioside-regulated excitatotory opioid receptor-mediated hyperalgesia, enhances opioid analgesia and attenuates tolerance in mice. Brain Res. 995 (2004) 260-266.

[11] H. Ono, Y. Nagano, N. Matsunami, S. Sugiyama, S. Yamamoto, M. Tanabe. Oseltamivir, an antiinfluenza virus drug, produces hypothermia in mice. Biol. Pharm. Bull. 31 (2008) 638-642.

[12] Y. Izumi, K. Tokuda, K.A. O'Dell, C.F. Zorumski, T. Narahashi. Neuroexcitatory actions of Tamiflu and its carboxylate metabolite. Neurosci. Lett. 426 (2007) 54-58.

[13] D. Sweeny, G. Lynch, A.M. Bidgood, W. Lew, K.Y.Wang, K.C. Cundy. Metabolism of the influenza neurominidase inhibitor prodrugoseltamivir in the rat. Drug Metab. Dispos. 28 (2000) 737-774.

[14] G. He, J. Massarella, P. Ward. Clinical pharmacokinetics of the prodrug oseltamivir and its active metabolic Ro 64-0802, Clin. Pharmacokinet. 37 (1999) 471-484.

[15] A. Hatori, T. Arai, K. Yanamoto, T. Yamasaki, Y. Kawamura, J. Yui, F. Konno, R. Nakao, K. Suzuki, M.R. Zhang. Biodistribution and metabolism of the anti-influenza drug [11C]oseltamivir and its active metabolite [11C]Ro 64-0802 in mice. Nucl. Med. Biol. 36 (2009) 47-55.

[16] W. Li, P.A. Escarpe, E.J. Eisenberg, K.C. Cundy, C. Sweet, K.J. Jakeman, J. Merson, W. Lew, M. Williams, L. Zhang, C.U. Kim, N. Bischofberger, M.S. Chen, D.B. Mendel. Identification of GS 4104 as an orally bioavailable prodrug of the influenza virus neurominidase inhibitor GS 4071. Antimicrob. Agents Chemother. 42 (1998) 647-653.

[17] M. Kurowski, C. Oo, H. Wiltshire. Oseltamivir distributes to influenza virus replication sites in the middle ear and sinuses. Clin. Drug Invest. 24 (2004) 49-53.

[18] M.E. Andersen. Tissue dosimetry in risk assessment, or what's the problem here anyway? In: Pharmacokinetics in Risk Assessment, Drinking Water and Health. pp 8-23 (1987), National Academy Press, Washington DC.

[19] WHO, International Programme on Chemical Safety, Characterization and Application of Physiologically Based Pharmacokinetic models in Risk Assessment. Harmonization Project Document, No. 9 (2010), WHO Press, Geneva 27, Switzerland.

[20] N. Parrott, B. Davies, G. Hoffmann, A. Koerner, T. Lave, E. Prinssen, E. Theogaraj, T. Singer. Development of a physiologically based model for Oseltamivir and simulation of pharmacokinetics in neonates and infants. Clin. Pharmacokinet. 50(9) (2011) 613-623.

[21] M. Boberg, M.Vrana, A. Mehrotra, R. E. Pearce, A. Gaedigk, D.K.Bhatt, J. S.Leeder, B. Prasad. AgeDependent Absolute Abundance of Hepatic Carboxylesterases (CES1 and CES2) by LC-MS/MS Proteomics: Application to PBPK Modeling of Oseltamivirln Vivo Pharmacokinetics in Infants, Drug Metab. Dispos. 45 (2017) 216-223.

[22] I. Nestorov. Whole body pharmacokinetic models. Clin. Pharmacokinet. 42 (2003) 883-908.

[23] Q. Chang, M.S.S Chow, Z. Zuo. Studies on the influence of esterase inhibitor to the pharmacokinetic profiles of oseltamivir and oseltamivir carboxylate in rats using an improved LC/MS/MS method. Biomed. Chromatogr. 23 (2009) 852-857. 
[24] N. Lindegardh, W. Hanpithakpong, Y. Wattanagoon, P. Singhasivanon, N.J. White, N.P.J. Day. Development and validation of a liquid chromatographic-tandem mass spectrometric method for determination of oseltamivir and its metabolite oseltamivir carboxylate in plasma, saliva and urine. $J$. Chromatogr. B 859 (2007) 74-83.

[25] O. Luttringer, F.P. Theil, P. Poulin, A.H. Schmitt-Hoffmann, T.W. Guentert, T. Lave. Physiologicallybased pharmacokinetic (PBPK) modeling of disposition of epiroprim in humans. J. Pharm. Sci. 92 (2003) 1990-2007.

[26] B. Davies, T. Morris. Physiological parameters in laboratory animals and humans. Pharm. Res. 10 (1993) 1093-1095.

[27] M.J. Angelo, A.B. Pritchard. Route-to-route extrapolation of dichloromethane exposure using a physiological pharmacokinetic model. In: Pharmacokinetics and in risk assessment: drinking water and health. National Academy Press, 1987 pp 254-264, Washington, DC.

[28] M.J. Anderton, M.M. Manson, R. Verschoyle, A. Gescher, W.P. Steward, M.L.Williams, D.E. Mager. Physiological modeling of formulated and crystalline 3,3'-diindolylmethane pharmacokinetics following oral administration in mice. Drug Metab. Dispos. 32 (2004) 632-638.

[29] J.M. Gallo, F.C. Lam, D.G. Perrier. Area method for the estimation of partition coefficients for physiological pharmacokinetic models. J. Pharmacokinet. Biopharm. 15 (1987) 271-280.

[30] Z. Ye, H. Gao, Approaches to measure protein binding of enzymatically unstable compounds in plasma, Bioanalysis 10 (2018) 451-459.

[31] K.B. Bischoff, R.L. Dedrick, D.S. Zaharko, J.A. Longstreth. Methotrexate Pharmacokinetics. J. Pharm. Sci. 60 (1971) 1128-1133.

[32] B.E. Davies. Pharmacokinetics of oseltamivir: an oral antiviral for the treatment and prophylaxis of influenza in diverse populations. J. Antimicrob. Chemother. 65 (Suppl. 2) (2010) ii5-ii10.

[33] S. Lennon, J. Barrett, C. Kirkpatrick, C. Rayner. Oseltamivir oral suspension and capsules are bioequivalent for the active metabolite in healthy adult volunteers. Int. J. Clin. Pharmacol. Ther. 47 (2009) 539-549.

[34] W.L. Chiou, G. Robbie, S.M. Chung, T.C. Wu, C. Ma. Correlation of plasma clearance of 54 extensively metabolized drugs between humans and rats: mean allometric coefficient of 0.66. Pharm. Res. 15 (1998) 1474-1479.

[35] T. Iwatsubo, N. Hirota, T. Ooie, H. Suzuki, N. Shimada, K. Chiba, T. Ishizaki, C.E. Green, C.A. Tyson, Y. Sugiyama. Prediction of in vivo drug metabolism in the human liver from in vitro metabolism data. Pharmacol. Ther. 73 (1997) 147-171.

[36] C.C. Travis. Interspecies and dose-route extrapolations, in: Pharmacokinetics in risk Assessment: Drinking Water and Health, Vol. 8. National Academy Press, 1987, Washington, D.C.

[37] F.J. Eisenberg, A. Bidgood, K.C. Cundy. Penetration of GS 4071, a novel influenza neuraminidase inhibitor into rat bronchoalveolar lining fluid following oral administration of the prodrug GS 4104 . Antimicrob. Agents Chemother. 41 (1997) 1949-1952.

[38] S. Bjorkman, D.R. Wada, D.R. Stanski, W.F. Ebling. Comparative physiological pharmacokinetics of fentanyl and alfentanil in rats and humans based on parametric single-tissue models. J. Pharmacokinet. Biopharmaceut. 22 (1994) 381- 410.

[39] H.J. Clewell, T.S. Lee, R.L. Carpenter. Sensitivity of physiologically based pharmacokinetic models to variation in model parameters: methylene chloride. Risk Anal. 14 (1994) 521-531.

[40] G. Gao, F.C.P. Law. Physiologically-based pharmacokinetics of matrine in the rat after oral administration of pure chemical and ACAPHA. Drug Metab. Dispos. 37 (2009) 884-91.

[41] C.Y. Quon, K. Mai, G. Patil, H.F. Stampfli. Species differences in the stereoselective hydrolysis of esmolol by blood esterases. Drug Metab. Dispos. 16 (1988) 425-428.

[42] S.S. Jhee, M. Yen, L. Ereshefsk. Low penetration of oseltamivir and its carbonylate into cerebrospinal fluid in healthy Japanese and Caucasian volunteers. Antimicrob. Agents Chemother. 52 (2008) 36873693. 
[43] A. Ose, H. Kusuhara, K. Yamatsugu, M. Kanai, M. Shibasaki, T. Fujita, A.Yamamoto, Y. Sugiyama. Pglycoprotein restricts the penetration of oseltamivir across the blood-brain barrier. Drug Metab. Dispos. 2 (2008) 427-434.

[44] G. Hoffmann, C. Funk, S. Fowler, M.B. Otteneder, A. Breidenbach, C.R. Rayner, T. Chu, E.P. Prinssen. Nonclinical Pharmacokinetics of Oseltamivir and Oseltamivir Carboxylate in the Central Nervous System. Antimicrob. Agents Chemother. 53 (2009) 4753-4761.

[45] C.H. Hsueh, V. Hsu, P. Zhao, L. Zhang, K.M. Giacomini. S.M. Huang, PBPK modeling of the effect of reduced kidney function on the pharmacokinetics of drugs excreted renally by organic anion transporters, Clin. Pharmacol. 103(3) (2018) 485-492.

\section{Appendix}

The mass balance equations for non-eliminating organs and tissues such as lung, brain, spleen, muscle, and the rest of body are as follows:

$$
\begin{aligned}
& v_{\mathrm{XY}} \frac{\mathrm{d} C_{\mathrm{XYP}}}{\mathrm{d} t}=Q_{\mathrm{XY}}\left(C_{\mathrm{BAP}}-\frac{C_{\mathrm{XYP}}}{R_{\mathrm{XYP}}}\right) \\
& v_{\mathrm{XY}} \frac{\mathrm{d} C_{\mathrm{XYC}}}{\mathrm{d} t}=Q_{\mathrm{XY}}\left(C_{\mathrm{BAP}}-\frac{C_{\mathrm{XYC}}}{R_{\mathrm{XYC}}}\right)
\end{aligned}
$$

where $\mathrm{XY}$ represents the lung, brain, spleen, muscle, and the rest of body. The terms $Q_{\mathrm{XY}}, V_{\mathrm{XY}}$ and $R_{\mathrm{XY}}$ represent tissue blood flow, volume and tissue/plasma partition coefficient, respectively; subscripts $p$ and $c$ represent $O P$ and $O C$, respectively.

Brain

$$
\begin{aligned}
& V_{\mathrm{BR}} \frac{\mathrm{d} C_{\mathrm{BRP}}}{\mathrm{d} t}=Q_{\mathrm{BR}}\left(C_{\mathrm{BAP}}-\frac{C_{\mathrm{BRP}}}{R_{\mathrm{BRP}}}\right) \\
& V_{\mathrm{BR}} \frac{\mathrm{d} C_{\mathrm{BRC}}}{\mathrm{d} t}=Q_{\mathrm{BR}}\left(C_{\mathrm{BAP}}-\frac{C_{\mathrm{BRC}}}{R C_{\mathrm{BRC}}}\right)
\end{aligned}
$$

Lung

$$
\begin{aligned}
& V_{\mathrm{LG}} \frac{\mathrm{d} C_{\mathrm{LGP}}}{\mathrm{d} t}=Q_{\mathrm{LG}}\left(C_{\mathrm{BVP}}-\frac{C_{\mathrm{LGP}}}{R_{\mathrm{LGP}}}\right) \\
& V_{\mathrm{LG}} \frac{\mathrm{d} C_{\mathrm{LGC}}}{\mathrm{d} t}=Q_{\mathrm{LG}}\left(C_{\mathrm{BVC}}-\frac{C_{\mathrm{LGC}}}{R C_{\mathrm{LGC}}}\right)
\end{aligned}
$$

\section{Gut contents}

$$
\begin{aligned}
& V_{\mathrm{GC}} \frac{\mathrm{d} C_{\mathrm{CGCP}}}{\mathrm{d} t}=-k f_{P}\left(C_{G C P} V_{G T}\right) \\
& V_{\mathrm{GC}} \frac{\mathrm{d} C_{\mathrm{CGCC}}}{\mathrm{d} t}=-k f_{C}\left(C_{G C C} V_{G T}\right)
\end{aligned}
$$

Kidney

$$
V_{\mathrm{KD}} \frac{\mathrm{d} C_{\mathrm{KDP}}}{\mathrm{d} t}=Q_{\mathrm{KD}}\left(C_{\mathrm{BAP}}-\frac{C_{\mathrm{KDP}}}{R_{\mathrm{KDP}}}\right)-\mathrm{CL}_{\mathrm{P}} C_{\mathrm{BAP}}
$$




$$
v_{\mathrm{KD}} \frac{\mathrm{d} C_{\mathrm{KDC}}}{\mathrm{d} t}=Q_{\mathrm{KD}}\left(C_{\mathrm{BAC}}-\frac{C_{\mathrm{KDC}}}{R_{\mathrm{KDC}}}\right)-\mathrm{CL}_{\mathrm{C}} C_{\mathrm{BAC}}
$$

Venous blood

$$
\begin{aligned}
& V_{\mathrm{BV}} \frac{\mathrm{d} C_{\mathrm{CBVP}}}{\mathrm{d} t}=Q_{\mathrm{FT}} \frac{C_{\mathrm{FTP}}}{R_{\mathrm{FTP}}}+Q_{\mathrm{HR}} \frac{C_{\mathrm{HRP}}}{R_{\mathrm{HRP}}}+Q_{\mathrm{KD}} \frac{C_{\mathrm{KDP}}}{R_{\mathrm{KDP}}}+Q_{\mathrm{MS}} \frac{C_{\mathrm{MSP}}}{R_{\mathrm{MSP}}}+Q_{\mathrm{LV}} \frac{C_{\mathrm{LVP}}}{R_{\mathrm{LVP}}}+ \\
& +Q_{\mathrm{BR}} \frac{C_{\mathrm{BRP}}}{R_{\mathrm{BRP}}}+Q_{\mathrm{RB}} \frac{C_{\mathrm{RBP}}}{R_{\mathrm{RBP}}}-Q_{\mathrm{C}} C_{\mathrm{BVP}} \\
& V_{\mathrm{BV}} \frac{\mathrm{d} C_{\mathrm{CBVC}}}{\mathrm{d} t}=Q_{\mathrm{FT}} \frac{C_{\mathrm{FTC}}}{R_{\mathrm{FTC}}}+Q_{\mathrm{HR}} \frac{C_{\mathrm{HRC}}}{R_{\mathrm{HRC}}}+Q_{\mathrm{KD}} \frac{C_{\mathrm{KDC}}}{R_{\mathrm{KDC}}}+Q_{\mathrm{MS}} \frac{C_{\mathrm{MSC}}}{R_{\mathrm{MSC}}}+Q_{\mathrm{LV}} \frac{C_{\mathrm{LVC}}}{R_{\mathrm{LVC}}}+ \\
& +Q_{\mathrm{BR}} \frac{C_{\mathrm{BRC}}}{R_{\mathrm{BRC}}}+Q_{\mathrm{RB}} \frac{C_{\mathrm{RBC}}}{R_{\mathrm{RBC}}}-Q_{\mathrm{C}} C_{\mathrm{BVC}}
\end{aligned}
$$

Mixed venous plasma

$$
\begin{gathered}
C_{\mathrm{PVP}}=\frac{C_{\mathrm{BVP}}}{\mathrm{BLPLR}_{\mathrm{P}}} \\
C_{\mathrm{PVC}}=\frac{C_{\mathrm{BVC}}}{\mathrm{BLPLR}_{\mathrm{C}}}
\end{gathered}
$$

$C_{\mathrm{PVP}}$ and $C_{\mathrm{PVC}}$ are the concentration in mixed venous plasma of $\mathrm{OP}$ and $\mathrm{OC}, C_{\mathrm{BVP}}$ and $C_{\mathrm{BVC}}$ are the concentration in mixed venous blood, BLPLR is the concentration ratio in blood and plasma.

Arterial blood

$$
\begin{aligned}
& V_{\mathrm{BA}} \frac{\mathrm{d} C_{\mathrm{BAP}}}{\mathrm{d} t}=Q_{\mathrm{C}}\left(\frac{C_{\mathrm{LGP}}}{R_{\mathrm{LGP}}}-C_{\mathrm{BAP}}\right) \\
& V_{\mathrm{BA}} \frac{\mathrm{d} C_{\mathrm{BAC}}}{\mathrm{d} t}=Q_{\mathrm{C}}\left(\frac{C_{\mathrm{LGC}}}{R_{\mathrm{LGC}}}-C_{\mathrm{BAC}}\right)
\end{aligned}
$$

Liver

$$
\begin{aligned}
& V_{\mathrm{LV}} \frac{\mathrm{d} C_{\mathrm{LVP}}}{\mathrm{d} t}=\left(Q_{\mathrm{LV}}-Q_{\mathrm{GU}}-Q_{\mathrm{SP}}\right) C_{\mathrm{BAP}}+Q_{\mathrm{GU}} \frac{C_{\mathrm{GUP}}}{R_{\mathrm{GUP}}}+Q S P \frac{C_{\mathrm{SPP}}}{R_{\mathrm{SPP}}}- \\
& -Q_{\mathrm{LV}} \frac{C_{\mathrm{LVP}}}{R_{\mathrm{LVP}}}-V_{\mathrm{max}, \mathrm{P}} \frac{C_{\mathrm{LVP}}}{R_{\mathrm{LVP}}\left(K_{\mathrm{m}, \mathrm{P}}+\frac{C_{\mathrm{LVP}}}{R_{\mathrm{LVP}}}\right)} \\
& V_{\mathrm{LV}} \frac{\mathrm{d} C_{\mathrm{LVC}}}{\mathrm{d} t}=\left(Q_{\mathrm{LV}}-Q_{\mathrm{GU}}-Q_{\mathrm{SP}}\right) C_{\mathrm{BAC}}+Q_{\mathrm{GU}} \frac{C_{\mathrm{GUC}}}{R_{\mathrm{GUC}}}+Q_{\mathrm{SP}} \frac{C_{\mathrm{SPC}}}{R_{\mathrm{SPC}}}- \\
& -Q_{\mathrm{LV}} \frac{C_{\mathrm{LVC}}}{R_{\mathrm{LVC}}}-V_{\text {max }, \mathrm{P}} R \frac{C_{\mathrm{LVP}}}{R_{\mathrm{LVP}}\left(K_{\mathrm{m}, \mathrm{P}}+\frac{C_{\mathrm{LVP}}}{R_{\mathrm{LVP}}}\right)}
\end{aligned}
$$




\section{Gut tissue}

$$
\begin{aligned}
& V_{\mathrm{GT}} \frac{\mathrm{d} C_{\mathrm{GTP}}}{\mathrm{d} t}=Q_{\mathrm{GT}}\left(C_{\mathrm{BAP}}-\frac{C_{\mathrm{GTP}}}{R_{\mathrm{GTP}}}\right)+\mathrm{RAO} \\
& V_{\mathrm{GT}} \frac{\mathrm{d} C_{\mathrm{GTC}}}{\mathrm{d} t}=Q_{\mathrm{GT}}\left(C_{\mathrm{BAC}}-\frac{C_{\mathrm{GTC}}}{R_{\mathrm{GTC}}}\right)
\end{aligned}
$$

where, $k_{\mathrm{f}}$ is the fecal excretion rate constant; $V_{\max }$ and $K_{\mathrm{m}}$ are the maximum metabolic rate for OP and the constant respectively; $R=\mathrm{MW}_{\mathrm{OC}} / \mathrm{MW}_{\mathrm{OP}}, \mathrm{MW}$ is molecular weight; $\mathrm{RAO}$ is OP input rate into the blood from the gut, $\mathrm{RAO}=k_{\mathrm{a}}(F)$ (dose) $\mathrm{e}^{-\mathrm{ka}(t-\mathrm{tag})}$, where $k_{\mathrm{a}}$ represents the absorption rate constant of OP, dose represents OP dosage, $F$ represents the apparent or empirical bioavailability factor, and $t_{\text {lag }}$ represents the lag times for absorption; $k_{f}$ is the fecal excretion rate constant; $\mathrm{CL}_{p}$ and $\mathrm{CL}_{c}$ are the renal clearance for $\mathrm{OP}$ and $\mathrm{OC}$, respectively. 